\title{
Trans-Cyclooctene-Functionalized PeptoBrushes with Improved Reaction Kinetics of the Tetrazine Ligation for Pretargeted Nuclear Imaging
}

E. Johanna L. Stéen, ${ }^{\dagger, \ddagger}, \nabla$ Jesper T. Jørgensen, ${ }^{\ddagger, \S}, \nabla$ Kerstin Johann, ${ }^{\perp, \nabla}$ Kamilla Nørregaard, ${ }^{\ddagger, \S}$ Barbara Sohr," Dennis Svatunek,,$^{\|}$Alexander Birke, ${ }^{\perp}$ Vladimir Shalgunov, ${ }^{\dagger, \S}$ Patricia E. Edem, ${ }^{\dagger, \ddagger, \S}$ Raffaella Rossin, ${ }^{\text {TI }}$ Christine Seidl, ${ }^{\perp}$ Friederike Schmid, ${ }^{\#}$ Marc S. Robillard, ${ }^{\text {If }}$ Jesper L. Kristensen, ${ }^{\dagger}$ (])

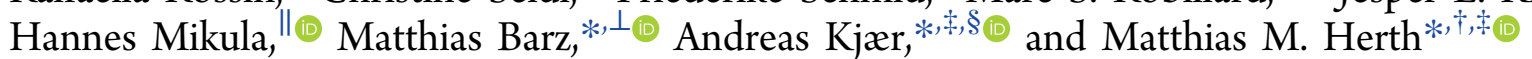

${ }^{\dagger}$ Department of Drug Design and Pharmacology, Faculty of Health and Medical Sciences, University of Copenhagen, Universitetsparken 2, 2100 Copenhagen, Denmark

${ }^{\ddagger}$ Department of Clinical Physiology, Nuclear Medicine \& PET, Rigshospitalet, Blegdamsvej 9, 2100 Copenhagen, Denmark

${ }^{\S}$ Cluster for Molecular Imaging, Department of Biomedical Sciences, University of Copenhagen, Blegdamsvej 3, 2100 Copenhagen $\emptyset$, Denmark

${ }^{\perp}$ Institute of Organic Chemistry, Johannes Gutenberg University, Duesbergweg 10-14, D-55099 Mainz, Germany

"Institute of Applied Synthetic Chemistry, Technische Universität Wien (TU Wien), Getreidemarkt 9, 1060 Vienna, Austria

${ }^{\text {II } T a g w o r k s ~ P h a r m a c e u t i c a l s, ~ G e e r t ~ G r o o t e p l e i n ~ 10, ~} 6525$ GA Nijmegen, The Netherlands

\#Institute of Physics, Johannes Gutenberg University, Staudingerweg 7-9, D-55099 Mainz, Germany

\section{Supporting Information}

ABSTRACT: Tumor targeting using agents with slow pharmacokinetics represents a major challenge in nuclear imaging and targeted radionuclide therapy as they most often result in low imaging contrast and high radiation dose to healthy tissue. To address this challenge, we developed a polymer-based targeting agent that can be used for pretargeted imaging and thus separates tumor accumulation from the imaging step in time. The developed targeting agent is based on polypeptide-graft-polypeptoid polymers (PeptoBrushes) functionalized with trans-cyclooctene (TCO). The complementary ${ }^{111}$ In-labeled imaging agent is a 1,2,4,5-tetrazine derivative, which can react with aforementioned TCO-modified PeptoBrushes in a

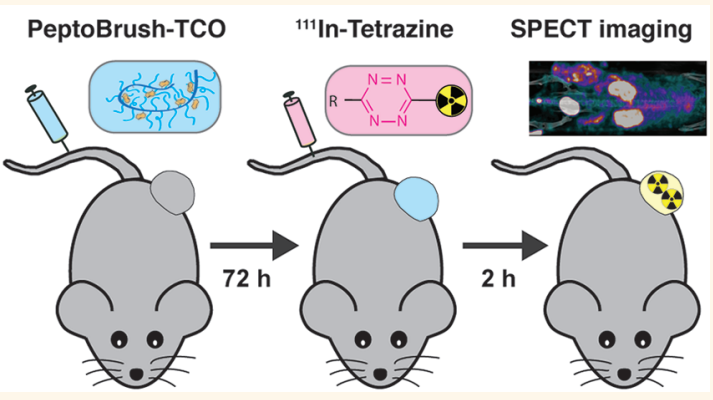
rapid bioorthogonal ligation. A high degree of TCO loading (up to 30\%) was achieved, without altering the physicochemical properties of the polymeric nanoparticle. The highest degree of TCO loading resulted in significantly increased reaction rates (77-fold enhancement) compared to those with small molecule TCO moieties when using lipophilic tetrazines. Based on computer simulations, we hypothesize that this increase is a result of hydrophobic effects and significant rearrangements within the polymer framework, in which hydrophobic patches of TCO moieties are formed. These patches attract lipophilic tetrazines, leading to increased reaction rates in the bioorthogonal ligation. The most reactive system was evaluated as a targeting agent for pretargeted imaging in tumor-bearing mice. After the setup was optimized, sufficient tumor-to-background ratios were achieved as early as $2 \mathrm{~h}$ after administration of the tetrazine imaging agent, which further improved at $22 \mathrm{~h}$, enabling clear visualization of CT-26 tumors. These findings show the potential of PeptoBrushes to be used as a pretargeting agent when an optimized dose of polymer is used.

KEYWORDS: pretargeted imaging, polypeptide-graft-polypeptoids, EPR effect, nanomedicine, SPECT, tetrazine ligation, PeptoBrush

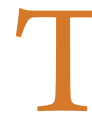

he application of nanotechnology for drug delivery, diagnosis, and targeted radionuclide therapy holds the potential to improve current strategies in cancer treatment. ${ }^{1}$ Nanomedicines such as polymers, liposomes,
Received: August 30, 2019

Accepted: December 10, 2019

Published: December 10, 2019 
Conventional nuclear imaging:
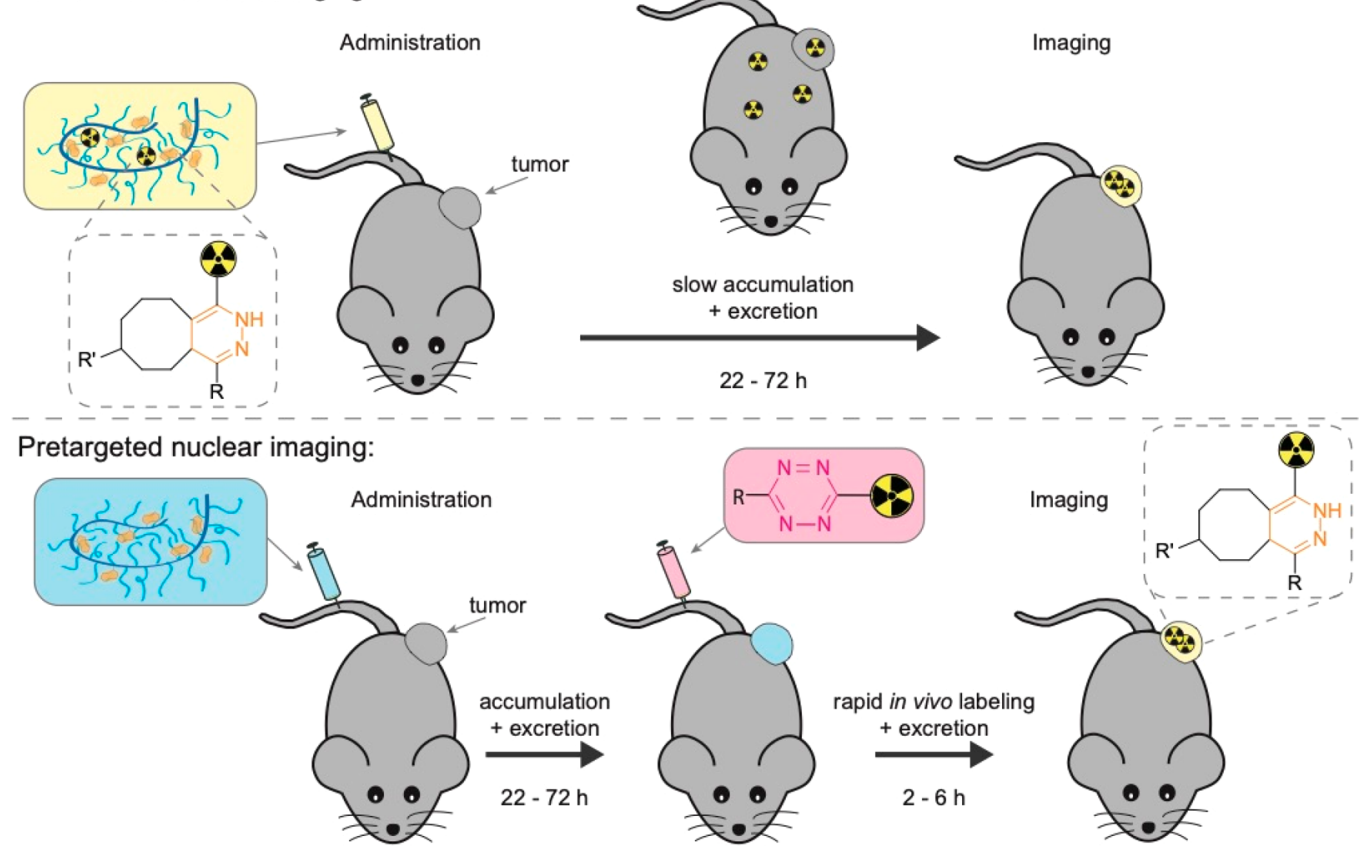

Figure 1. Illustration of conventional nuclear imaging compared to pretargeted nuclear imaging of a tumor targeting nanomedicine using the tetrazine ligation. Here, the nanomedicine, which acts as the primary targeting agent, is a polymer modified with trans-cyclooctene (TCO), and the secondary imaging agent is a radiolabeled 1,2,4,5-tetrazine $(\mathrm{Tz})$. In conventional nuclear imaging, the nanomedicine is radiolabeled (yellow box), administered, and allowed to circulate for days to achieve tumor accumulation and sufficient systemic clearance for imaging (usually a time frame of 22-72 h). In pretargeted nuclear imaging, the TCO-modified primary targeting agent (blue box) is administered and allowed to circulate until tumor accumulation and sufficient systemic clearance has been achieved. Thereafter, the radiolabeled Tz (pink box) is administered, imaging is performed within the first few hours as the bioorthogonal reaction between TCO and Tz, and the excretion of Tz proceeds rapidly.

micelles, and inorganic nanoparticles facilitate accumulation and retention at tumor sites, thereby toxicity to healthy tissue is reduced substantially. ${ }^{2}$ The passive accumulation of nanomedicines into tumors is enabled by the enhanced permeability and retention (EPR) effect. This widely discussed phenomenon, which has been shown in a variety of tumor types, comes as a result of leaky tumor vasculature and impaired lymphatic drainage. ${ }^{3}$ Recently, the clinical relevance of this effect has been demonstrated; for example, the treatment response of liposomal doxorubicin, a nanomedicine, has shown a positive correlation with the extent of EPR-mediated tumor uptake. ${ }^{4-9}$ Although the EPR effect provides an attractive route to deliver nanomedicines to solid tumors, it is a highly complex process with considerable variations among patients with tumors of the same type, as well as within the same tumor. ${ }^{7,10,11}$ Factors arising from the physicochemical properties of the specific nanomedicine (e.g., size, shape, composition, and surface characteristics) and the tumor microenvironment (e.g., vascularization and interstitial fluid pressure) are known to influence the tumor accumulation. ${ }^{2,4-6}$ Hence, methods that can identify likely responders to a given nanomedicine from larger patient cohorts are needed. Medical imaging techniques such as single-photon emission computed tomography (SPECT) or positron emission tomography (PET) can be used to assess the biodistribution and tumor accumulation of a specific radiolabeled nanomedicine in a patient. ${ }^{2,8,12,13}$

Current attempts to utilize radiolabeled nanomedicines for imaging in the clinic are often challenged by slow pharmacokinetics. As a result, high target accumulation through the EPR effect and good image contrast can only be achieved after several days. ${ }^{14}$ Therefore, to match the biological life of nanomedicines, long-lived radionuclides are required. This inherently results in high radiation doses to healthy tissues, which consequently limits or even prohibits clinical application. ${ }^{15-17}$ A promising strategy that can be applied to address these challenges is pretargeting. This two-step procedure separates the targeting from the imaging step, thereby facilitating the use of short-lived radionuclides in combination with slowly accumulating nanomedicines. In pretargeting approaches, the nanomedicine (primary targeting agent) is first administered intravenously (i.v.) and allowed to accumulate at its target site over a sufficient period of time. Second, a rapidly distributing and excreting radiolabeled probe (secondary imaging agent) is administered and interacts or binds to the preadministered nanomedicine in vivo (Figure 1). ${ }^{18-20}$

Selective reaction between the secondary imaging agent and the primary targeting agent at the tumor site can be achieved by the use of bioorthogonal chemistry. ${ }^{21}$ At present, the fastest bioorthogonal reaction is the tetrazine ligation, wherein a 1,2,4,5-tetrazine $(\mathrm{Tz})$ reacts with a dienophile, usually transcyclooctene (TCO) (Figure 1). ${ }^{22}$ This ligation shows high selectivity and impressive reaction kinetics (rate constants up to $10^{6} \mathrm{M}^{-1} \mathrm{~s}^{-1}$ ), which makes it an exceptionally useful tool for pretargeting strategies. $^{20,23-26}$

So far, almost all pretargeting studies based on the tetrazine ligation have used TCO-functionalized monoclonal antibodies $(\mathrm{mAb}) .^{27-32}$ As an alternative, biodegradable TCO-functionalized polymers with dimensions relevant for EPR-mediated tumor accumulation could be used as the primary targeting agent and may even provide the potential to increase the TCO content, to better shield TCO moieties or enhance stability in circulation. $^{33-35}$ We have recently shown that the biological 
Scheme 1. Synthesis of PeptoBrushes 1-3 by Nucleophilic Ring-Opening Polymerization and Sequential Attachment of TCO Moieties and pSar Side Chains onto the pGlu Backbone ${ }^{a}$

A

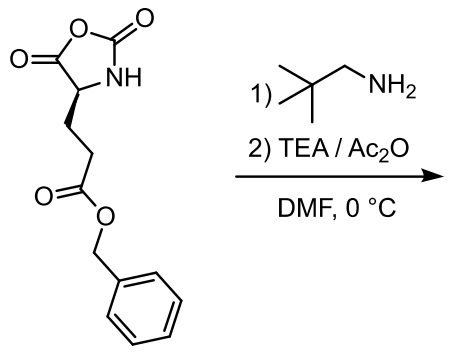

5<smiles>CCC(C)NC(CC(=O)OCc1ccccc1)C(C)=O</smiles>

TFA / $\mathrm{HBr}(48 \%(v / v)$, RT<smiles>CCC(=O)N(CCC(=O)O)C(CCC(=O)O)C(C)NCC(C)(C)C</smiles>

7

B<smiles>CCC(=O)NC(CCC(=O)O)C(CC)NC(C)=O</smiles>

7

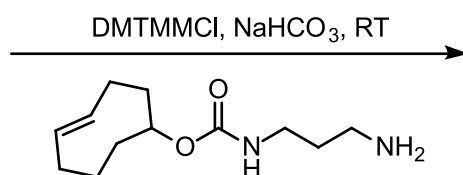

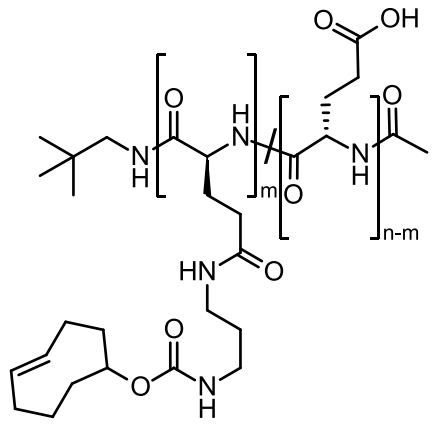

9-11

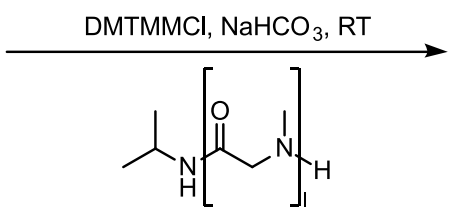

$\bigwedge_{\mathrm{NH}_{2}} \uparrow_{\mathrm{DMF}, \mathrm{RT}}^{12}$<smiles>CN1CC(=O)OC1=O</smiles>

13

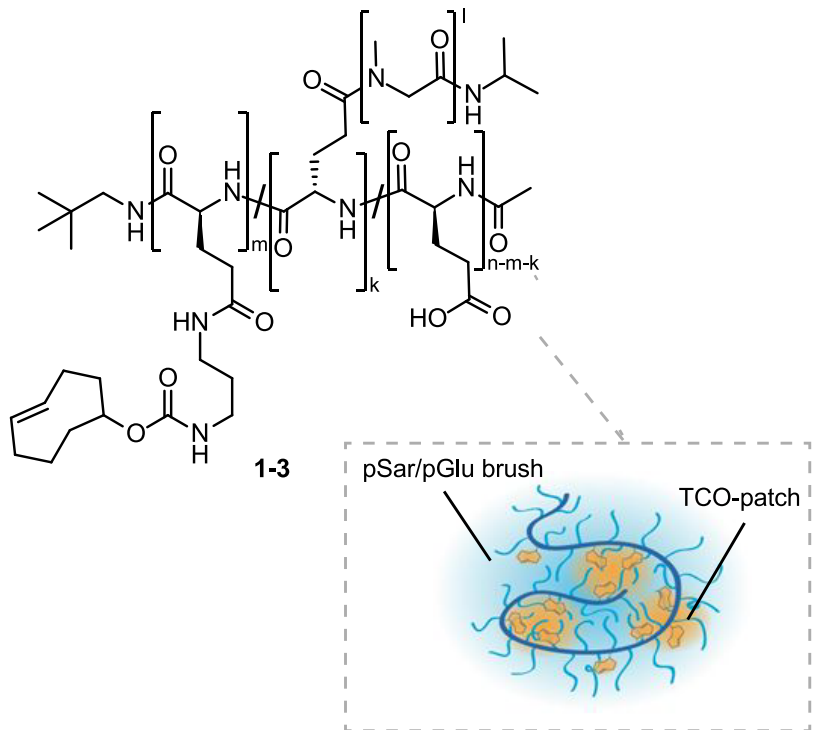

${ }^{a}$ Conditions: (A) Synthesis of pGlu backbone. (B) Functionalization of the pGlu backbone with TCO moieties and pSar side chains. Inset: Sketch of the core-shell structure of PeptoBrushes 1-3. The TCO moieties are bound to a polymer and located within hydrophobic TCO patches (yellow), which attract lipophilic Tz derivatives; $n=100, k=$ pSar grafting density, $m=$ TCO loading (see Table 1 ).

half-life of TCO moieties could be prolonged to reasonable time frames for pretargeted imaging (up to approximately 10 days) when they are attached in close proximity to the mAb. ${ }^{36}$ This enhanced in vivo stability was suggested to be a result of a shielding effect from the $\mathrm{mAb}$ toward $\mathrm{Cu}$-containing serum proteins, which cause isomerization of TCO to its less reactive cis-isomer. As a comparison, the half-life of TCO connected to a mAb via a $\mathrm{PEG}_{10}$ chain was approximately two times shorter. ${ }^{37}$
Designing TCO-functionalized polymers with a hydrophilic shell and a hydrophobic core may provide the same shielding effect when TCO moieties are located inside the hydrophobic core, while still being accessible for tetrazines. For this purpose, polypeptide-graft-polypeptoid copolymers based on polyglutamic acid (pGlu)/polysarcosine (pSar) moieties (PeptoBrushes) appear to be ideal candidates. They can be used to build up core-shell structures that allow for high loading of lipophilic 

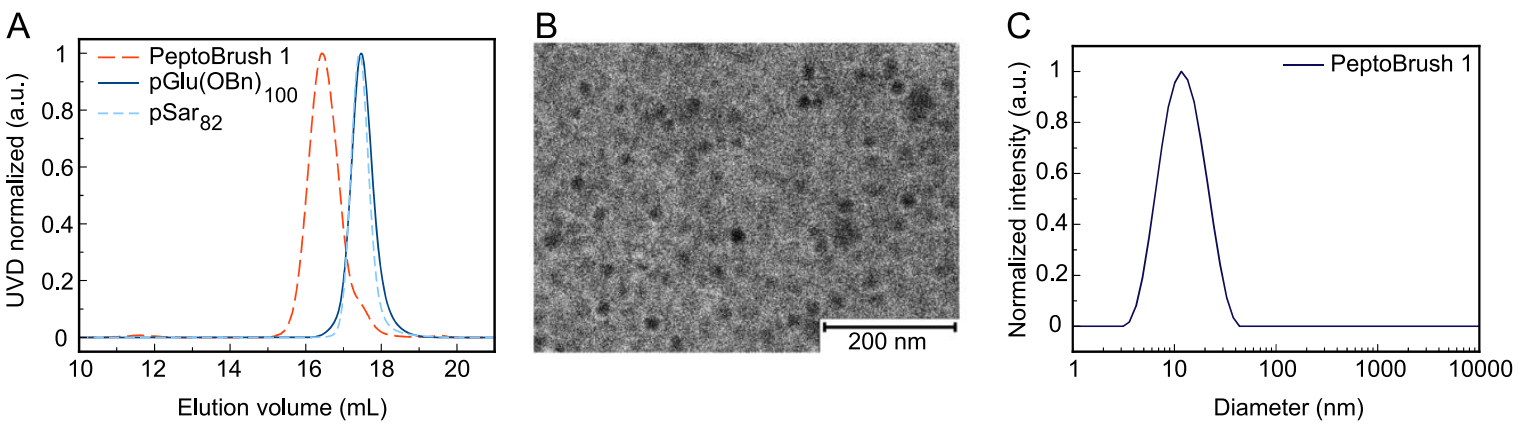

Figure 2. Analysis of PeptoBrush 1. (A) SEC characterization of pGlu(OBn) ${ }_{100}, \mathrm{pSar}_{82}$, and PeptoBrush 1. (B) CryoTEM image of $1 \mathrm{~g} / \mathrm{L}$ PeptoBrush 1. (C) Dynamic light scattering $\left(173^{\circ}\right)$ of purified PeptoBrush 1 (SEC and DLS of PeptoBrushes 2, 3, and 4, respectively, can be found in the SI).

Table 1. Characteristics for Synthesized Polymers

\begin{tabular}{|c|c|c|c|c|c|c|c|c|}
\hline polymer & $\begin{array}{c}\text { yield } \\
(\%)\end{array}$ & $\mathrm{DP}^{a}$ & $\underset{(\%)}{\operatorname{grafting} \text { density pSar }}{ }^{b}$ & $\begin{array}{c}\mathrm{TCO}^{\text {loading }^{c} \text { (groups per }} \\
\text { polymer) }\end{array}$ & $\begin{array}{c}M_{n}^{d} \\
(\mathrm{~kg} / \mathrm{mol})\end{array}$ & $\boxplus^{b, e}$ & $D_{\mathrm{h}}^{f, g}(\mathrm{~nm})$ & $\begin{array}{c}\zeta \text {-potential } \\
(\mathrm{mV})\end{array}$ \\
\hline pGlu(OBn) 6 & 97 & $100^{c}$ & & & 13.0 & 1.13 & & nd \\
\hline pSar 12 & 98 & $82^{h}$ & & & 5.9 & 1.10 & 4 & nd \\
\hline PeptoBrush 1 & 39 & $100 / 82$ & 24 & 30 & 160 & 1.21 & $11 \pm 0.1$ & $-3.17 \pm 0.29$ \\
\hline PeptoBrush 2 & 25 & $100 / 82$ & 27 & 13 & 180 & 1.19 & $10 \pm 0.1$ & $-4.94 \pm 1.66$ \\
\hline PeptoBrush 3 & 20 & $100 / 82$ & 28 & 8 & 180 & 1.21 & $10 \pm 0.1$ & $-7.44 \pm 0.99$ \\
\hline PeptoBrush 4 & 30 & $100 / 82$ & 26 & & 170 & 1.20 & $11 \pm 0.2$ & $-9.71 \pm 1.44$ \\
\hline
\end{tabular}

${ }^{a}$ The degree of polymerization (DP) is the number of monomeric units in the polymer. ${ }^{b}$ Determined by SEC in HFIP relative to PMMA standards. ${ }^{c}$ Determined by ${ }^{1} \mathrm{H}$ NMR in $\mathrm{D}_{2} \mathrm{O}$ or DMSO- $d_{6 \cdot}{ }^{d}$ The number average molecular weight. ${ }^{e}$ The dispersity value $(\nexists)$ corresponds to the distribution

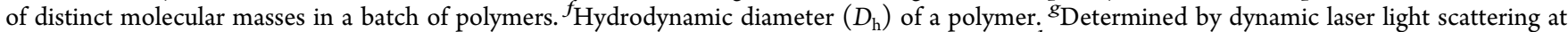
$173^{\circ}$ in $10 \mathrm{mM} \mathrm{NaCl}$ solution. Values represent mean \pm standard of mean (SEM) from $n=3 .{ }^{h}$ Determined by SEC in HFIP relative to PMMA and pSar standards; nd $=$ not determined.

compounds, such as TCO moieties, without the risk of aggregation and with the possibility to shield these moieties against degradation. ${ }^{38-41}$ Moreover, these types of polymers are reported to be highly biocompatible (nontoxic and nonimmunogenic $)^{38-40,42}$ and have previously been used for EPRmediated tumor targeting. ${ }^{40,43,44}$

Herein, we describe the development and evaluation of TCOfunctionalized PeptoBrushes based on a pGlu backbone and hydrophilic pSar side chains forming a stealth-like shell around the unimolecular nanoparticle. The PeptoBrushes were functionalized with different degrees of TCO moieties in order to study the influence of various TCO loadings on the performance of the tetrazine ligation. In contrast to micelles, these graft architectures do not allow for a complete phase separation between hydrophobic TCO moieties and hydrophilic pSar polymers. Instead, they form individual hydrophobic patches. These patches may be the right balance between accessibility and steric shielding to enhance TCO stability toward enzymes but maintain TCO reactivity toward low molecular weight $\mathrm{Tz}$ imaging agents. Ultimately, we aimed to evaluate the potential of these PeptoBrushes to be used as primary targeting agents for pretargeted SPECT imaging. Subsequent experiments were planned to be carried out in a mouse tumor model CT26 (murine colorectal cancer) showing a pronounced EPR effect.

\section{RESULTS AND DISCUSSION}

Design, Synthesis, and Characterization of TCOFunctionalized Polypeptide-graft-Polypeptoid Copolymer Brushes (PeptoBrushes). The applied PeptoBrushes consist of a pGlu backbone to which hydrophobic TCO moieties and hydrophilic pSar chains are attached, forming a molecular brush polymer. We hypothesized that this polymer architecture may improve the reaction kinetics of the tetrazine ligation because the ligation appears to be controlled by the reaction probability rather than by diffusion. This was concluded by comparing typical $\mathrm{Tz}$ derivative diffusion constants with typical tetrazine ligation rates in solution. This observation implies that the rate constant should increase in the presence of an attractive potential that keeps the reactants close to each other. This situation is given within PeptoBrushes. The Smoluchowski theory describes the coagulation/diffusion of small particles in solution over time. ${ }^{45}$ It can be used to calculate the reaction rate increase, which we hypothesize to exist within PeptoBrushes. Indeed, calculations based on the Smoluchowski theory indicated that the rate constant of the tetrazine ligation should increase by a factor of approximately 3 when lipophilic $\mathrm{Tz}$ derivatives are reacted with PeptoBrushes (see Supporting Information (SI)). These preliminary calculations convinced us to synthesize four different PeptoBrushes with different degrees of TCO loading (0, 7.5, 15, and 30\%) and, consequently, evaluate their reaction kinetics experimentally.

Polymers 1-3 were obtained via grafting of TCO moieties and pSar polymers onto a pGlu acid backbone (Scheme 1$){ }^{38}$ The hydrophobic pGlu(OBn) backbone (6) was synthesized by nucleophilic ring-opening polymerization of $\gamma$-benzyl-L-glutamic acid $N$-carboxyanhydride (5), initiated by neopentylamine. After an acidic deprotection of the benzyl groups of intermediate 6, the pGlu backbone 7 was obtained in a yield of $97 \%$. The chain length of 7 consisted of 100 monomer units, which was determined by proton nuclear magnetic resonance spectroscopy $\left({ }^{1} \mathrm{H}\right.$ NMR). The pGlu backbone (7) was then functionalized with various amounts of TCO moieties via amide coupling of (E)-cyclooct-4-en-1-yl(3-aminopropyl)carbamate (8) to the 
A<smiles>Cc1nnc(-c2cccc(-c3c(C)c4ccc(N)cc4oc3=O)c2)nn1</smiles>

14 (HELIOS 347Me)<smiles>Cc1nnc(C)nn1</smiles>

17<smiles>Cc1nnc(-c2cccc(-c3c(C)c4cc5c(cc4oc3=O)NCCC5)c2)nn1</smiles>

15 (HELIOS 388Me)<smiles>CC(C)(COC(C)(C)CO)NC(=O)OC1CC/C=C\CCC1</smiles>

16

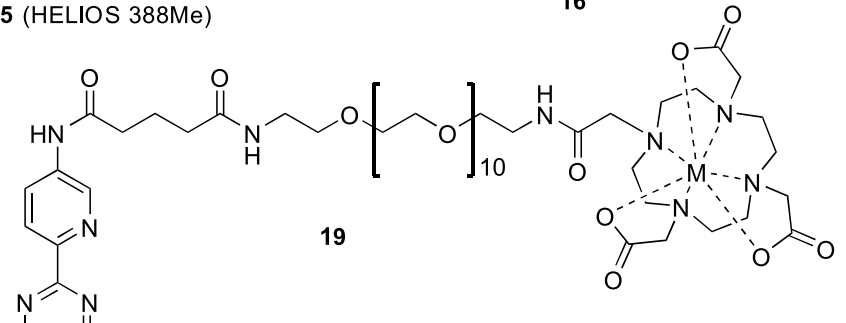

18<smiles>c1ccc(-c2nnc(-c3ccccn3)nn2)nc1</smiles><smiles>N=C(N=[V])c1ccccn1</smiles>

B<smiles>Cc1nnc(-c2cccc(-c3c(C)c4cc5c(cc4oc3=O)NCCC5)c2)nn1</smiles>

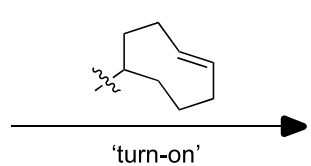

high fluorescence

C

fluorogenic $T z(14,15)$

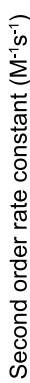

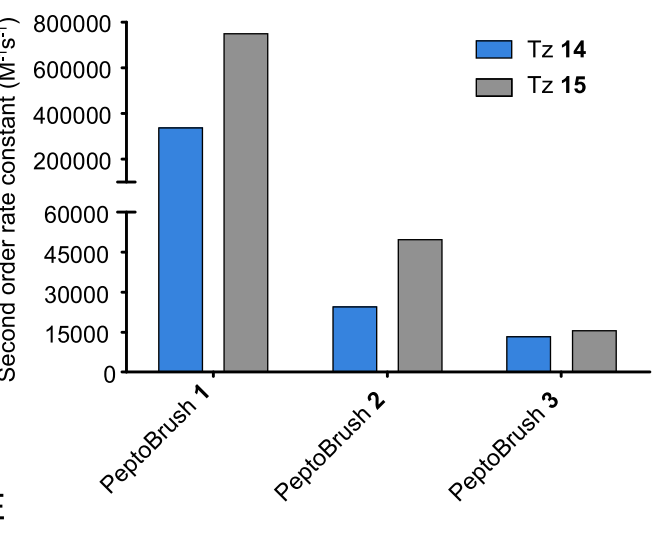

D
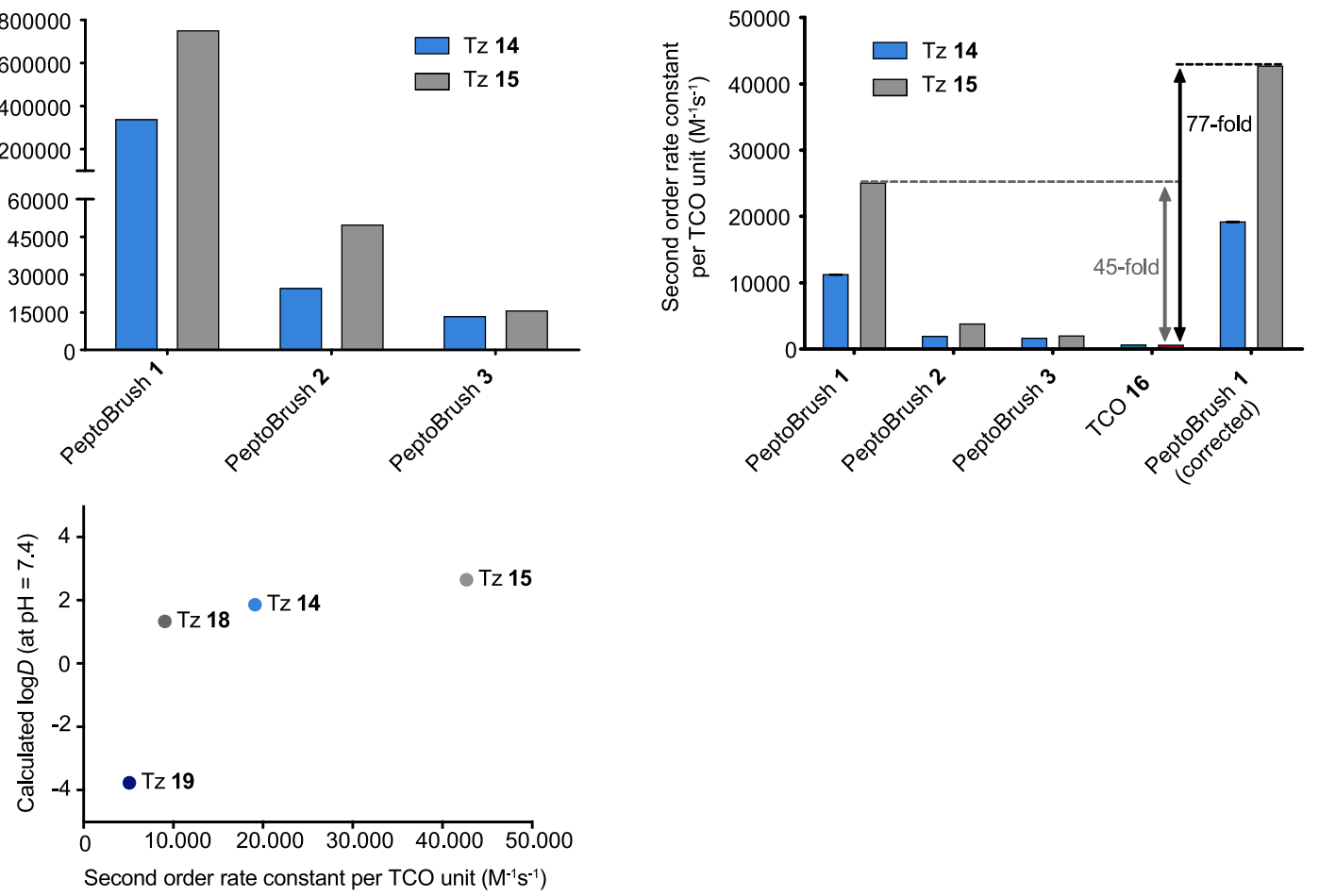

Figure 3. Reaction kinetics for the tetrazine ligation of PeptoBrushes. (A) Fluorogenic "turn-on" Tz 14 and 15 and water-soluble TCO derivative 16 used for kinetic investigations by stopped-flow spectrometry. (B) "Turn-on" of fluorogenic HELIOS probes 14 and 15 by reaction with TCO. (C) Measured second-order rate constants in PBS at $37^{\circ} \mathrm{C}$ for PeptoBrushes 1-3. (D) Measured second-order rate constants per single TCO unit $(n=5$, SD $<0.5 \%)$. Data for PeptoBrush 1 (corrected) is based on reactive TCO units per polymer as determined by reaction with 17 and $U V$ /vis spectroscopy. (E) Correlation of the reaction rate of PeptoBrush 1 with the lipophilicity $\left(C \log D_{7.4}\right.$ values) of Tz 14, 15, 18, and 19. $C \log D_{7.4}$ values were calculated using the software Chemicalize. For Tz 19, M = metal ion.

carboxylic acid groups of 7 for PeptoBrushes 1-3. Purification of the respective polymers (9-11) was achieved by dialysis and subsequent lyophilization. We aimed for an incorporation of 7.5,
15 , and $30 \%$ TCO moieties to be able to correlate the degree of TCO functionalization with the reaction rates of the tetrazine ligation. The degree of functionalization was determined by ${ }^{1} \mathrm{H}$ 


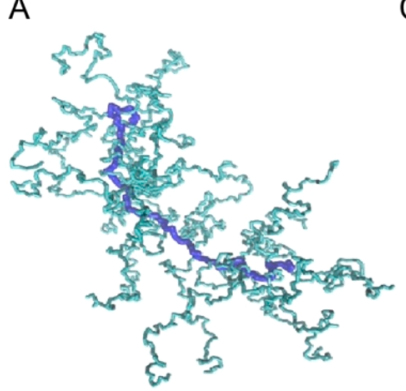

B

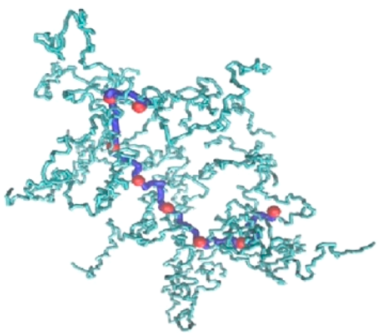

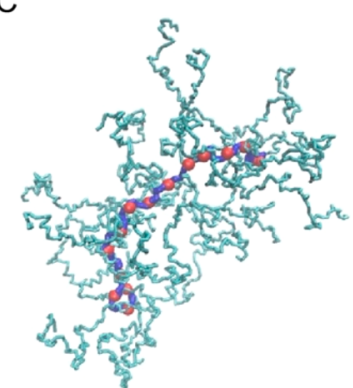

$\mathrm{E}$

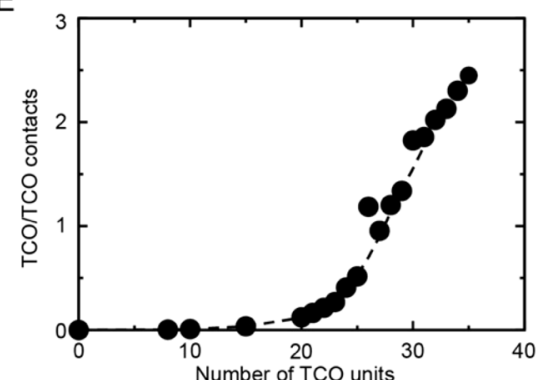

D

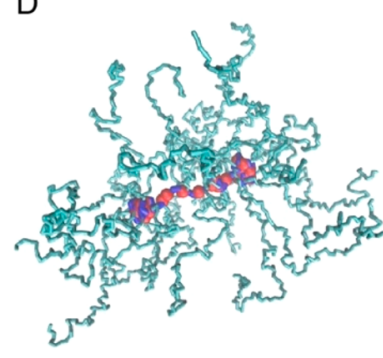

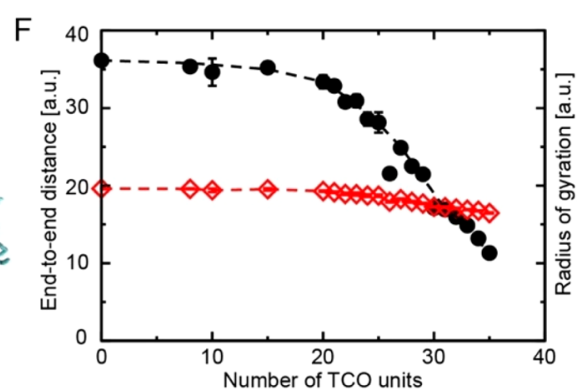

Figure 4. Coarse-grained simulations of PeptoBrushes with different degrees of TCO loading. Red dots $=$ TCO units $/$ patches, blue line $=p$ Glu backbone, turquoise side chains $=$ pSar. $(\mathrm{A}-\mathrm{D})$ Simulation snapshots with 0, 8, 15, and $30 \mathrm{TCO}$ units. (E) Average numbers of TCO/TCO contacts per TCO unit (see SI). (F) End-to-end distance of backbone chain (black) and radius of gyration of the whole brush (red) versus number of TCO units. Lines are a guide for the eye. The snapshots were produced using the VMD package. ${ }^{50}$

NMR through quantification of the alkene protons (5.4-5.8 ppm) against the initiator protons. PeptoBrushes $1-3$ showed a TCO functionalization of 8,13 , and $30 \%$. Finally, as outlined in Scheme 1, the pSar homopolymer (12) was prepared using an analogous ring-opening polymerization strategy as described for pGlu(OBn) (6) but starting from sarcosine $N$-carboxyanhydride (13). ${ }^{38}$ The pSar 12 was isolated in a yield of $98 \%$, and the degree of polymerization (DP) was determined to be 82 and a dispersity value $(\boxplus)$ of 1.10 was detected by size exclusion chromatography (SEC) in hexafluoroisopropanol (HFIP).

Thereafter, 12 was grafted onto 7 to obtain PeptoBrush 4 and onto the remaining carboxylic acid groups of TCO-functionalized pGlu backbones 9-11 (Figure 2A and SI Figures S1-S3). We aimed for a maximal incorporation of $\mathrm{pSar}$ side chains, which resulted in an amount of $26 \%$ pSar units for PeptoBrush 4 and 24-28\% pSar units for PeptoBrushes 1-3 (Table 1). The resulting PeptoBrushes $\mathbf{1 - 4}$ were successfully purified by spinfiltration, lyophilized, and analyzed via single-angle (zetasizer) and multiangle dynamic light scattering (DLS), as well as cryogenic transmission electron microscopy (cryoTEM) (Figure 2B,C and SI Figures S2-S4). Spherical shapes with diameters of $10-11 \mathrm{~nm}$ were observed for all polymers, underlining the formation of single chain polymer nanoparticles. However, the internal structure could not be visualized by electron microscopy, likely due to the small size of polymer brushes in solution. Table 1 displays the characteristics for the synthesized benzyl-protected pGlu backbone (6), pSar (12), and PeptoBrushes 1-4.

Reaction Kinetics of PeptoBrushes. The reactivity of the PeptoBrushes 1-3 in the tetrazine ligation was studied by monitoring the reaction with fluorogenic "turn-on" $\mathrm{Tz}$ derivatives HELIOS $347 \mathrm{Me}(\mathbf{1 4})$ and HELIOS $388 \mathrm{Me}(\mathbf{1 5})^{46}$ (Figure 3A) in a buffered aqueous environment. Reaction of 14 and $\mathbf{1 5}$ with a dienophile leads to a significantly increased fluorescence ("turn-on", Figure 3B), enabling real-time monitoring of the reaction progress. For comparison, the rate constants of the reactions of $\mathbf{1 4}$ and $\mathbf{1 5}$ with the water-soluble TCO derivative $16^{47}$ were determined. Kinetic investigations were performed by monitoring reactions in phosphate-buffered saline (PBS) by stopped-flow spectrometry (with fluorescence detection).

Measured second-order rate constants for the ligation of the Tz derivatives $\mathbf{1 4}$ and $\mathbf{1 5}$ with PeptoBrushes $\mathbf{1 - 3}$ were in the range of 13000 to $750000 \mathrm{M}^{-1} \mathrm{~s}^{-1}$ (Figure $3 \mathrm{C}$ and SI Table S1). Calculation of the rate constants per single TCO unit (i.e., TCO moiety) revealed that the measured reaction rates (per TCO) far exceeded those of the used TCO control compound 16 when reacting with 14 and 15 . The highest rate of $>25000 \mathrm{M}^{-1} \mathrm{~s}^{-1}$ per TCO unit was observed for the reaction of $\mathbf{1 5}$ with PeptoBrush 1, providing a 45-fold increase compared to the rate constant of the reaction of 15 with 16 (Figure 3D). For the reactions of PeptoBrush 2 and PeptoBrush 3 with 15, the rate constants per TCO increased by a factor of 7 and 3.5, respectively, compared to the reaction of $\mathbf{1 5}$ and $\mathbf{1 6}$ (SI Table S2). Interestingly, these results indicate that more lipophilic $\mathrm{Tz}$ derivatives are more reactive toward PeptoBrushes 1-3. For example, the rate constant for $\mathbf{1 5}$ is more than twice as high as that for the more hydrophilic Tz 14 when reacted with PeptoBrush 1. Such an increase was not observed using the TCO control compound 16 (SI Table S2).

With PeptoBrush 1 exhibiting the highest reaction rates, further experiments were conducted. To verify whether the TCO loading of PeptoBrush 1 (as determined by ${ }^{1} \mathrm{H}$ NMR) was consistent with the number of TCO units effectively participating in the ligation, PeptoBrush 1 was reacted with 3,6-dimethyltetrazine (17), and the characteristic absorption of $\mathrm{Tz} 17$ was monitored by UV/vis spectroscopy. This titration revealed that only 17.6 out of the 30 TCO units per PeptoBrush were accessible for the ligation, which in turn implies higher reaction rates per TCO unit and, thus, an even higher acceleration of up to 77-fold for the reaction with 15 (Figure 3D, PeptoBrush 1 (corrected)). Next, we investigated if the 
Scheme 2. ${ }^{111}$ In Labeling of PeptoBrush 1 via Ligation to Tz $\left[{ }^{111} \mathrm{In}\right] 20$, Yielding the ${ }^{111}$ In-Labeled Version of PeptoBrush 1 $\left(\left[{ }^{111} \operatorname{In}\right] 21\right)^{a}$
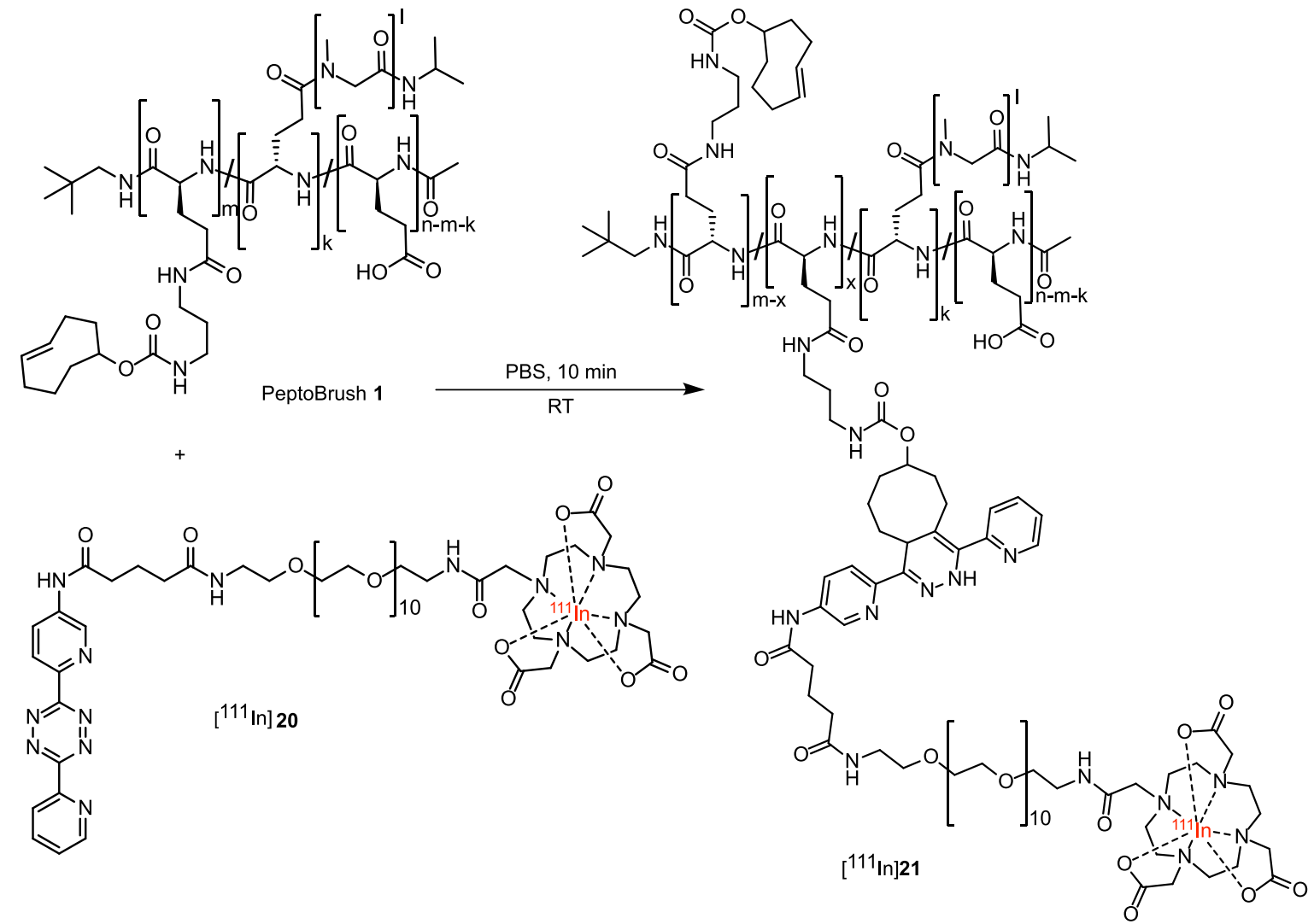

$a_{n}=100, m=30-x, x=$ unknown, $k=24$ (see Table 1$)$.

observed acceleration was in fact related to the lipophilicity of the used tetrazines. In this respect, we also determined the rate constants of the more hydrophilic $\mathrm{Tz}$ derivatives 18 and 19 (compared to 14 and 15) using UV/vis spectroscopy (Figure 3E and SI Table S1). A strong dependency between the measured reaction rates in correlation to the calculated logarithmic distribution coefficient at physiological $\mathrm{pH}\left(C \log D_{7.4}\right)$ values for all investigated $\mathrm{Tz}$ derivatives was found. These results further support the hypothesis that more lipophilic $\mathrm{Tz}$ derivatives facilitate higher reaction rates.

Finally, the influence of the biologic environment on the observed acceleration effect was studied. In this respect, the reaction rate between PeptoBrush 1 and Tz 15 was investigated in full cell growth medium (Dulbecco's modified Eagle's medium, DMEM, including 10\% fetal bovine serum, FBS) by stopped-flow spectrometry. A lower but still significantly increased reaction rate (17-fold) compared to the reaction of 15 with TCO 16 was observed in this medium (SI Table S1). Consequently, we hypothesized that the rate constant acceleration effect of lipophilic Tz derivatives and TCO moieties within PeptoBrush $\mathbf{1}$ is also present in vivo, but the degree of acceleration is dependent on the surrounding media.

Theoretical Explanation of the Observed Rate Constant Acceleration Effect. The Smoluchowski theory can explain a rate constant increase of about 3 if a typical binding energy win between nonpolar groups on the order of $0.7 \mathrm{kcal} /$ mol is assumed per lipophilic Tz/TCO interaction (see SI). ${ }^{48}$ Such rate constant increases are observed for PeptoBrushes 2 and 3. However, the enormous rate constant increase (77-fold) between PeptoBrush 1 and 15 cannot solely be explained by the
Smoluchowski theory. Significant rearrangements of polymer chains are needed to increase the rate constant to such levels. Thereby, proximal TCO units have to cooperatively create binding sites with increased affinity to lipophilic $\mathrm{Tz}$ derivatives on the order of $2 \mathrm{kcal} / \mathrm{mol}$. This value corresponds to numbers usually obtained by interaction of 2-3 hydrophobic binding sites. In order to explore if a higher degree of TCO functionalization leads to massive polymer chain rearrangement and an increased number of affinity binding sites, coarse-grained simulations of the PeptoBrushes were performed. Here, a functionalization of $0,8,15$, and $30 \%$ TCO units was used.

Simulations were carried out using a simple spring-bead model in which the polymer units are described as beads connected with massless virtual harmonic springs. ${ }^{49}$ TCO units were treated as polymer units connected to a backbone string. The units exhibit, beside the harmonic potential of the virtual springs, nonpolar interactions on the order of $0.7 \mathrm{kcal} / \mathrm{mol}$ per TCO/TCO interface. Subsequent simulations showed that polymer chains significantly rearranged for high TCO loading, whereas TCO remained isolated in PeptoBrushes with low TCO content (Figure 4A-D). In the case of the highest load (30 units), TCO units within a single PeptoBrush aggregated and formed internal hydrophobic patches (Figure 4D). Within these patches, lipophilic $\mathrm{Tz}$ derivatives find nonpolar areas where they interact with more than one TCO unit. The attractive interaction within these areas can easily reach values above 2 $\mathrm{kcal} / \mathrm{mol}$. As such, an enormous rate constant increase is expected when nonpolar patches are formed. Figure 4E illustrates that the number of $\mathrm{TCO} / \mathrm{TCO}$ contacts per unit sharply increases when the number of TCO units exceeds 25 . At 


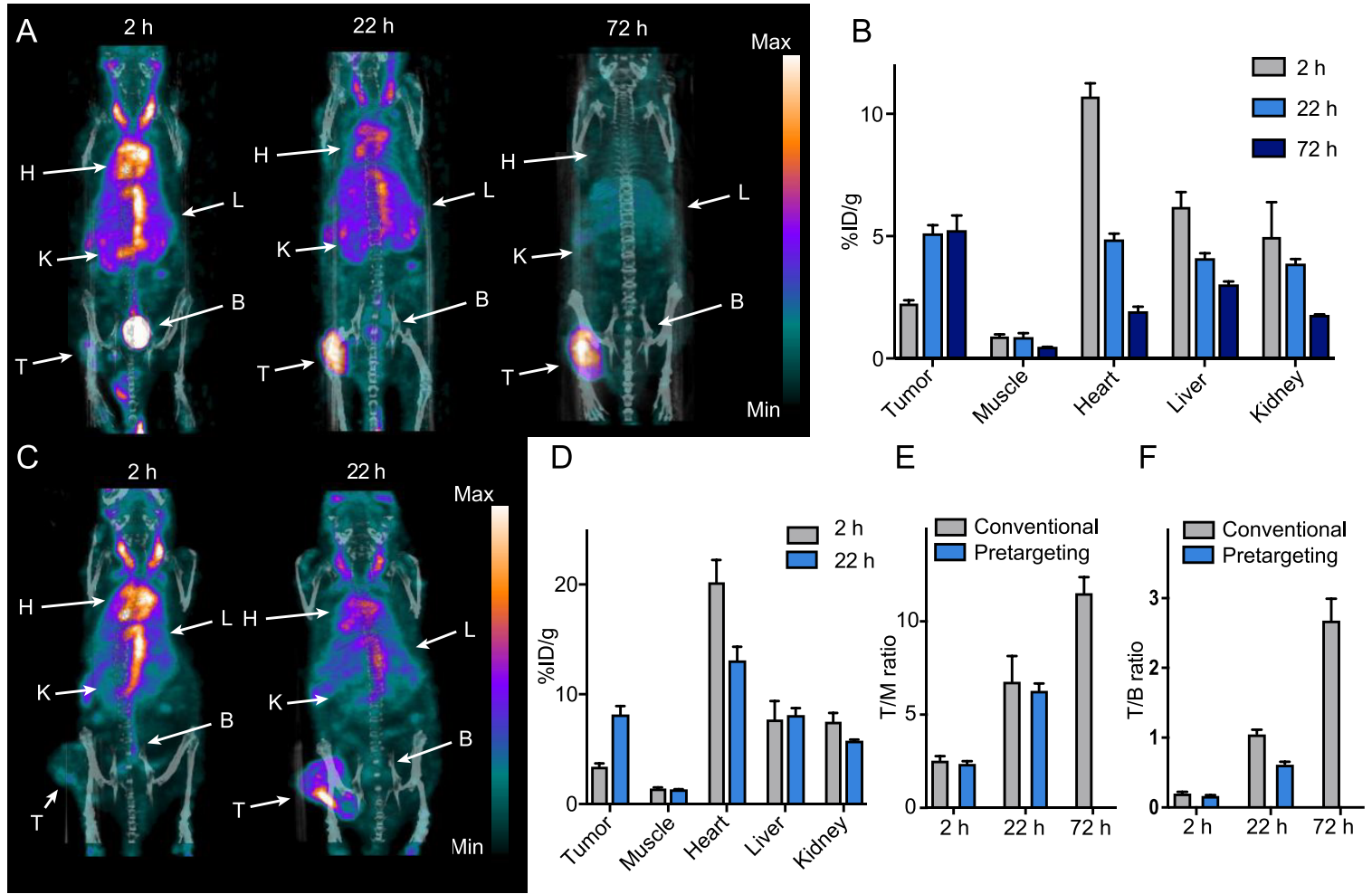

Figure 5. Evaluation of PeptoBrush 1 as a primary targeting agent for pretargeted imaging. Conventional imaging. (A) Representative SPECT/ CT images (maximum intensity projection) at 2, 22, and $72 \mathrm{~h}$ after injection of $\left[{ }^{111} \mathrm{In}\right] 21 \mathrm{in}$ CT26 tumor-bearing mice. Each image is scaled between its minimum and maximum pixel intensity. (B) Image derived mean uptake values $(\% \mathrm{ID} / \mathrm{g})$ in tissues $(n=4)$. Pretargeted imaging. (C) Representative SPECT/CT images (maximum intensity projection) at 2 and $22 \mathrm{~h}$ p.i. of $\left[{ }^{111} \mathrm{In}\right] 20 \mathrm{in}$ CT26 tumor-bearing mice pretreated with PeptoBrush 1. (D) Image derived mean uptake values $(\% \mathrm{ID} / \mathrm{g})$ in tissues $(n=4)$. Comparison. (E) Tumor-to-muscle (T/M) ratios from conventional and pretargeted SPECT imaging. (F) Tumor-to-blood (T/B) ratios from conventional and pretargeted SPECT imaging. Data are shown as mean and standard error of mean $(\mathrm{SEM})$. Abbreviations: $\mathrm{H}=$ heart, $\mathrm{L}=$ liver, $\mathrm{K}=$ kidney, $\mathrm{B}=\mathrm{bladder}$, and $\mathrm{T}=\mathrm{tumor}$.

this number, hydrophobic patches are formed and a massive acceleration of the rate constant between these TCO patches and lipophilic $\mathrm{Tz}$ derivatives is expected to occur. Interestingly, the overall radius of gyration of the PeptoBrush remained almost constant with increased numbers of $\mathrm{TCO} / \mathrm{TCO}$ contacts, whereas the end-to-end distance of the backbone chain decreased (Figure 4F). This is perfectly in line with the dynamic light scattering data for PeptoBrushes 1-4.

Stability of PeptoBrush 1 in Human Plasma. As PeptoBrush 1 showed the highest reactivity, this polymer was selected for further evaluation studies in tumor-bearing mice. However, before performing the in vivo evaluation, the behavior of PeptoBrush 1 in human plasma was studied. Even though polypeptide-graft-polypeptoid copolymers have been shown to be biocompatible and not prone to aggregation in vivo, ${ }^{39}$ alteration of the graft copolymer microstructure and the incorporation of hydrophobic TCO moieties within the pGlu backbone may alter this behavior and result in aggregation with serum proteins. In light of this, the behavior of PeptoBrush $\mathbf{1}$ in human serum was studied by DLS. ${ }^{51}$ No aggregation was detected between human serum proteins and PeptoBrush $\mathbf{1}$ at a concentration of $50 \mathrm{mg} / \mathrm{L}$ (SI Figure S7). This concentration is on the order of previously reported concentrations required for pretargeting approaches in vivo, and as such, no aggregation of these structures was expected to occur in vivo. ${ }^{27,35}$ The plasma half-life of TCO moieties in PeptoBrush 1 was determined to be 1.9 days (see SI for experimental procedures), which is comparable to observed half-lives of TCO moieties attached to mAbs. Compared to free TCO moieties, the plasma half-life increased approximately 14-fold. ${ }^{37}$

Evaluation of PeptoBrush 1 as a Potential Primary Targeting Agent. With no aggregation as well as with a reasonable plasma half-life of TCO moieties in PeptoBrush 1, in vivo evaluation experiments were initiated. In order to investigate if PeptoBrush $\mathbf{1}$ could be used for tumor targeting, we first used conventional SPECT imaging to study the biodistribution of the polymer over time. Thus, PeptoBrush 1 was radiolabeled with the long-lived radionuclide indium-111 $\left({ }^{111} \mathrm{In}, t_{1 / 2}=2.8\right.$ days). Radiolabeling succeeded via ligation to a previously described ${ }^{111}$ In-labeled $\mathrm{Tz}$ derivative ([ $\left.\left.{ }^{111} \mathrm{In}\right] 20\right)$ (Scheme 2). ${ }^{27}$ The reaction was conducted at room temperature in PBS, and full consumption of $\left[{ }^{111} \mathrm{In}\right] 20$ was observed within less than $10 \mathrm{~min}$. The following evaluation in tumor-bearing mice was carried out with the assumption that the in vivo behavior between the radiolabeled version of PeptoBrush 1 ([ $\left.\left.{ }^{111} \mathrm{In}\right] 21\right)$ and PeptoBrush 1 only differs negligibly.

$\left[{ }^{111} \mathrm{In}\right] 21(50 \mathrm{MBq} / 150 \mu \mathrm{L}$ of PBS with an apparent specific activity $\left(A_{\mathrm{s}}\right)$ of $\left.109 \mathrm{MBq} / \mathrm{mg}\right)$ was injected i.v. into mice $(n=4)$ bearing subcutaneous CT26 tumors (mouse colorectal cancer). This tumor model was chosen as it generally shows a pronounced EPR effect. ${ }^{52}$ Small animal SPECT/CT imaging was carried out at 2, 22, and $72 \mathrm{~h}$ postinjection (p.i.). Visual inspection of the images showed that radiolabeled PeptoBrush 1 $\left(\left[{ }^{111} \mathrm{In}\right] 21\right)$ accumulated selectively in CT26 tumors. Uptake kinetics were slow with an initial large fraction of radioactivity in blood that decreased over time. Consequently, tumor uptake and contrast improved gradually and significantly (Figure 5A). 

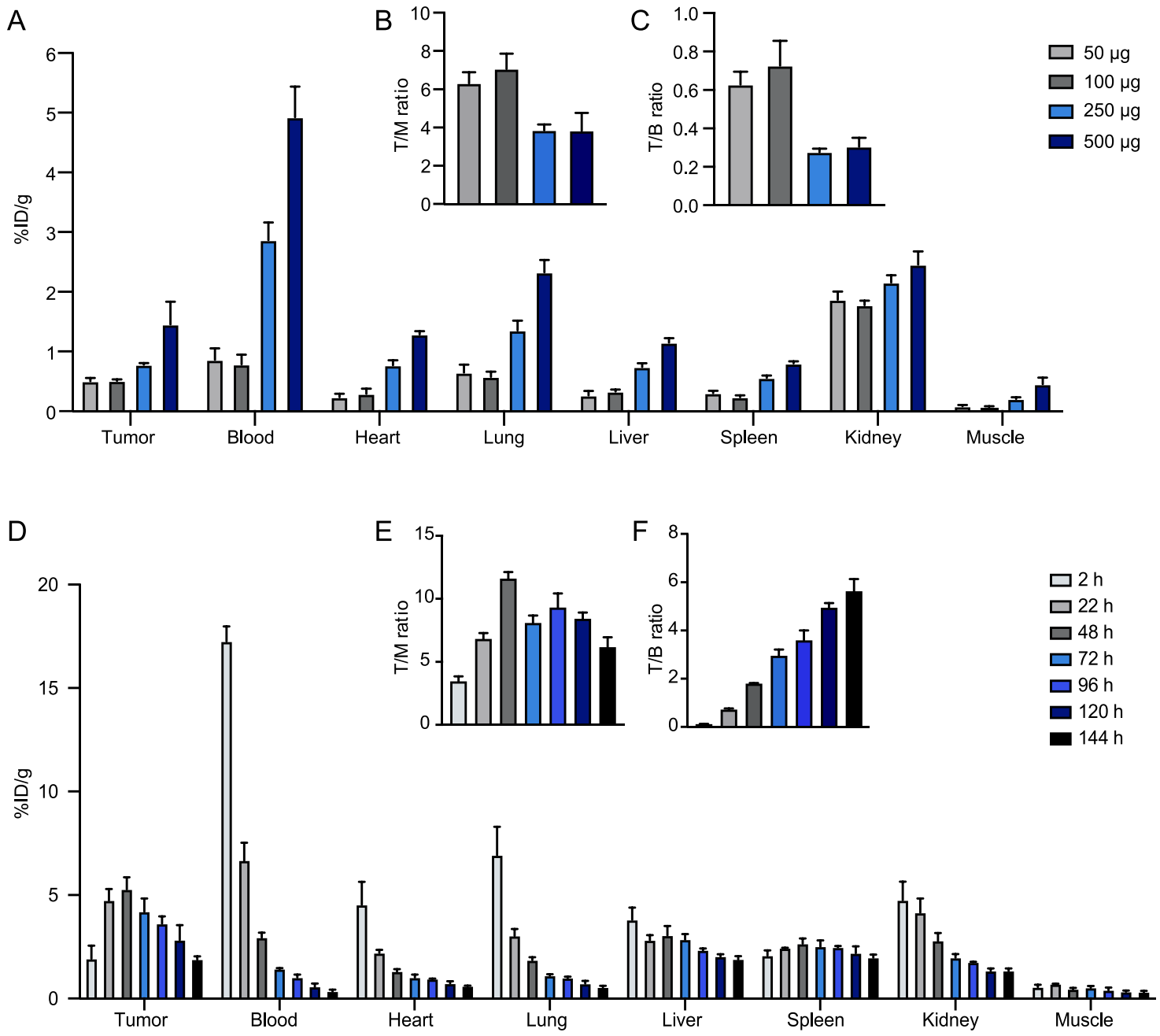

Figure 6. (A) Ex vivo biodistribution showing tissue uptake (\%ID/g), (B) tumor-to-muscle (T/M) ratio, and (C) tumor-to-blood (T/B) ratio, 2 h p.i. of [ $\left.{ }^{111} \mathrm{In}\right] 20$ in CT26 tumor-bearing mice injected with 50, 100, 250, or $500 \mu \mathrm{g}$ of PeptoBrush $172 \mathrm{~h}$ earlier $(n=4)$. Data are shown as mean and standard error of mean (SEM) (D) Ex vivo biodistribution showing uptake values (\% $\mathrm{ID} / \mathrm{g}),(\mathrm{E})$ tumor-to-muscle (T/M) ratios, and (F) tumor-to-blood $(\mathrm{T} / \mathrm{B})$ ratios at different time points for CT26 tumor-bearing mice injected with $100 \mu \mathrm{g}$ of $\left[{ }^{111} \mathrm{In}\right] 21(n=3$ for each time point). Data are shown as mean and standard error of mean (SEM).

Quantification showed that the mean tumor uptake ( \pm standard error of mean (SEM)) increased approximately 2 -fold from initially $2.3 \pm 0.1 \% \mathrm{ID} / \mathrm{g}$ (at $2 \mathrm{~h}$ p.i.) to $5.1 \pm 0.3 \% \mathrm{ID} / \mathrm{g}$ (at $22 \mathrm{~h}$ p.i.). No significant change in uptake was observed between 22 and $72 \mathrm{~h}$ p.i. (Figure 5B). Considering the average tumor accumulation of polymer-based nanomedicines, which is on the order of $0.7 \% \mathrm{ID} / \mathrm{g}$, the observed accumulation of $5-6 \%$ is very satisfactory. ${ }^{53}$ Tumor-to-background ratios were determined using the hind leg muscle tissue and the heart as surrogates for nontarget tissue and blood, respectively. Best ratios were achieved at $72 \mathrm{~h}$ p.i. with a tumor-to-muscle $(\mathrm{T} / \mathrm{M})$ ratio of 11.6 and a tumor-to-blood (T/B) ratio of 2.8 (Figure 5E,F). Lower ratios were observed at earlier time points (SI Table S4). Signal from well perfused organs (e.g., liver and kidney) were relatively high $(5-6 \% \mathrm{ID} / \mathrm{g}) 2 \mathrm{~h}$ p.i. but decreased over time.

Next, we explored the capability of PeptoBrush 1 to function as a primary targeting agent for pretargeted imaging. For this purpose, the same ${ }^{111} \mathrm{In}$-labeled $\mathrm{Tz}\left(\left[{ }^{111} \mathrm{In}\right] 20\right)$, which was used for conventional imaging was applied as a secondary imaging agent. Even though this $\mathrm{Tz}$ is too hydrophilic to achieve the observed accelerating effect in reaction kinetics upon ligation with PeptoBrush 1 (Figure 3E), it was selected because it has previously been used successfully in pretargeting strategies using TCO-modified mAbs. ${ }^{27,36,37}$ Thereby, using $\left[{ }^{111} \mathrm{In}\right] \mathbf{2 0}$ would allow us to study the performance of PeptoBrush $\mathbf{1}$ as a primary targeting agent without questioning the in vivo efficacy of the applied $\mathrm{Tz}$ imaging agent. We chose to use a lag time of $72 \mathrm{~h}$ between administration of PeptoBrush 1 and $\left[{ }^{111}\right.$ In $] 20$ because a good tumor-to-background contrast had been observed at this time point using conventional imaging. First, PeptoBrush 1 (1 mg in $100 \mu \mathrm{L}$ of PBS) was administered to CT26 tumor-bearing mice and $72 \mathrm{~h}$ later $\left[{ }^{111} \mathrm{In}\right] 20(\sim 50 \mathrm{MBq}, 100 \mu \mathrm{L}$, with a molar activity $\left(A_{\mathrm{m}}\right)$ of $\left.5.4 \mathrm{GBq} / \mu \mathrm{mol}\right)$ was injected. The molar amount of $\left[{ }^{111} \mathrm{In}\right] \mathbf{2 0}$ was adjusted to $11 \mathrm{nmol} /$ mouse by adding the precursor $(\mathrm{Tz} 19)$ of $\left[{ }^{111} \mathrm{In}\right] 20$ to the injection solution. The $\mathrm{TCO} / \mathrm{Tz}$ ratio was 17 at the time of injection. Animals were scanned using SPECT/CT 2 and 22 h p.i. and gained images subsequently analyzed (Figure 5C,D). Mean tumor accumulation $( \pm$ SEM) increased significantly from $3.4 \pm 0.3 \% \mathrm{ID} / \mathrm{g}$ (at $2 \mathrm{~h}$ p.i.) to $8.1 \pm 0.8 \% \mathrm{ID} / \mathrm{g}$ (at $22 \mathrm{~h}$ p.i.). Notably, these tumor uptake values are significantly higher, both after 2 and $22 \mathrm{~h}$, than the uptake values obtained using conventional imaging.

It is important to keep in mind that the uptake values from pretargeted imaging do not, like conventional imaging, give a 
measure for the fraction of polymer that accumulates in tissue. Instead, it provides a quantification of the administered $\mathrm{Tz}$ fraction that binds to the polymer accumulated in the respective tissue. Thereby, different tumor uptake values are expected for conventional imaging compared to pretargeted imaging. Our observation that higher tumor uptake was reached in the pretargeted study at later time points $(22 \mathrm{~h})$ is in contrast to the vast majority of current literature that reports that a higher tumor accumulation is achieved by conventional imaging within this time frame. However, there is no theoretical limitation preventing pretargeting in reaching higher accumulation values. To exclude that the observed uptake is due to nonspecific tumor binding, we determined the biodistribution of $\left[{ }^{111} \mathrm{In}\right] \mathbf{2 0}$. No significant tumor accumulation of $\left[{ }^{111} \mathrm{In}\right] 20$ occurred when no primary targeting agent was injected prior to administration of $\left.{ }^{[111} \mathrm{In}\right] 20$ at all time points (SI Figure S14). Interestingly, the observed tumor accumulation, especially the increase between the 2 and $20 \mathrm{~h}$ time point, cannot solely be explained from ligation of $\left[{ }^{111} \mathrm{In}\right] 20$ to PeptoBrush 1 at the tumor site, given that the ligation between PeptoBrush 1 and $\left[{ }^{111} \mathrm{In}\right] 20$ is extremely fast, and the biological half-life of $\left[{ }^{111} \mathrm{In}\right] 20$ is only $9.8 \mathrm{~min} .{ }^{21} \mathrm{We}$ suggest that the detected tumor increase is a result from both initial ligation between $\left[{ }^{111} \mathrm{In}\right] \mathbf{2 0}$ and PeptoBrush $\mathbf{1}$ at the tumor site and by EPR-mediated uptake of in vivo labeled PeptoBrush 1 that was formed in the blood pool within the first minutes upon injection of $\left[{ }^{111} \mathrm{In}\right] 20$. This hypothesis is supported by the fact that high radioactivity levels are observed in heart and aorta in SPECT images at $2 \mathrm{~h}$ p.i. and that these activity levels decrease over time (Figure $5 \mathrm{C}, \mathrm{D}$ ). This accumulation profile could also not be observed in mice that were not pretreated with PeptoBrush 1, but a similar accumulation profile was observed in conventional imaging. In conclusion, the pretargeting study resulted in a higher tumor uptake, but the image contrast was not improved compared to the conventional imaging. An increased tumor accumulation is usually beneficial for targeted radionuclide therapy. Therefore, the observed higher radioactivity levels in tumor tissue indicates that pretargeted radionuclide therapy with PeptoBrush $\mathbf{1}$ could potentially improve not only healthy tissue dosimetry but also the absolute dose delivered to the target. In order to reach the full potential of the polymer for radiotherapy, accumulation in healthy tissue, especially in blood, has to be substantially reduced. In other preclinical studies of pretargeting, this has been achieved by using a clearing or masking agent. ${ }^{54}$

Despite the high tumor uptake, low $\mathrm{T} / \mathrm{M}$ and $\mathrm{T} / \mathrm{B}$ ratios, especially at the early $2 \mathrm{~h}$ time point (Figure 5E,F), are not ideal for pretargeted imaging as this process should optimally be performed within a few hours. From a clinical perspective, a long waiting time for adequate imaging contrast complicates logistics, increases expenses, and enhances the risk that a patient will not appear for a scheduled scan. Moreover, the ability to image at an early time point allows for radiolabeling of $\mathrm{Tz}$ derivatives with short-lived radionuclides, which in turn lowers the radiation dose for the patient.

Based on these considerations, we decided to optimize the dose as well as the timing of PeptoBrush $\mathbf{1}$ administration with the aim to improve the tumor-to-background ratio at earlier time points $(2 \mathrm{~h})$.

Optimization of the Pretargeting Strategy with Respect to Dosing and Timing. Experiments for dose optimization were performed with the same pretargeting setup applied previously. Four different doses of PeptoBrush 1 (50, 100,250 , or $500 \mu \mathrm{g}$ dissolved in $100 \mu \mathrm{L}$ of PBS) were examined.
Animals were euthanized at $2 \mathrm{~h}$ p.i. for ex vivo biodistribution studies. Tissues were resected and weighed, and the fraction of $\left[{ }^{111} \mathrm{In}\right] \mathbf{2 0}$ in each tissue was determined using a gamma counter. Administration of low doses of PeptoBrush 1 (50 and $100 \mu \mathrm{g}$ ) resulted in relatively low tumor uptake of $\left[{ }^{111} \mathrm{In}\right] 20$. However, in animals receiving the higher doses $(250$ and $500 \mu \mathrm{g})$, this also led to an increased tumor uptake of 1.5 - and 3-fold, respectively (Figure 6A and SI Table S5). In contrast, higher tumor-tobackground ratios (approximately 3-fold) were observed for both lower doses (Figure 6B,C), and consequently, these doses are preferred for imaging.

In a next step, we aimed to identify the optimal lag time between injection of PeptoBrush 1 and $\left[{ }^{111} \mathrm{In}\right] 20$. The optimal timing for administration of $\left[{ }^{111} \mathrm{In}\right] 20$, the secondary imaging agent, is when the primary targeting agent, PeptoBrush 1, has accumulated sufficiently in the tumor and cleared as much as possible from background tissues. Ex vivo studies were carried out to investigate this using the optimized dose of $\left[{ }^{111} \mathrm{In}\right] 21$ (10 $\mathrm{MBq}, 100 \mu \mathrm{L}, 100 \mu \mathrm{g}$ apparent $A_{\mathrm{s}}=101 \mathrm{MBq} / \mathrm{mg}$ ). Animals were euthanized at designated time points between 2 and $144 \mathrm{~h}$ p.i. ( $n=3$ for each time point), and the biodistribution was determined (Figure 6D). As expected, based on the results from conventional SPECT imaging with the $1 \mathrm{mg}$ dose of $\left[{ }^{111} \mathrm{In}\right] \mathbf{2 1}$, the mean tumor uptake increased between 2 to $48 \mathrm{~h}$ p.i. and started to linearly decrease afterward until the end of the study (Figure 6D). The muscle uptake was relatively stable over time; hence the $\mathrm{T} / \mathrm{M}$ ratio followed the same trend (Figure $6 \mathrm{E}$ ). Uptake in blood, lung, and kidney decreased nearly exponentially from 2 to $144 \mathrm{~h}$ p.i. Subsequently, T/B ratios increased almost linearly over time (Figure 6F). Overall, the initial and continuous increase in tumor uptake of $\left[{ }^{111} \mathrm{In}\right] 21$ from 2 to $48 \mathrm{~h}$ was expected as it is EPR-mediated accumulation. However, the following decrease was not expected. We believe that this decrease is partly due the biodegradability of polypeptide-graftpolypeptoids, which should be more pronounced after 48 h. ${ }^{38-40,42}$ Control experiments were carried out using a dose of $500 \mu \mathrm{g}\left[{ }^{111} \mathrm{In}\right] 21$ (SI Figure S15). Although slightly higher tumor uptake was initially achieved at $48 \mathrm{~h}$ p.i. (approximately $20 \%$ ), the same trend was observed compared to the results obtained within the $100 \mu \mathrm{g}$ dose study.

On the basis of these results, we decided to use a dose of 100 $\mu \mathrm{g}$ and a lag time of $72 \mathrm{~h}$ for a new set of pretargeting studies. The reasons for using a lag time of $72 \mathrm{~h}$ were as follows: even though the tumor uptake and $\mathrm{T} / \mathrm{M}$ ratio peaked at $48 \mathrm{~h}$ p.i., the $\mathrm{T} / \mathrm{B}$ ratio continued to increase over time, and a large decrease in the blood uptake was detected between 48 and $72 \mathrm{~h}$ p.i. A later time point than $72 \mathrm{~h}$ was not chosen, despite improved $\mathrm{T} / \mathrm{B}$ ratio in the conventional imaging study because we determined a plasma half-life of 1.9 days of TCO moieties in PeptoBrush 1. Therefore, longer time frames could lead to a lower probability of the tetrazine ligation occurring.

Pretargeted Imaging with PeptoBrush 1 under Optimized Conditions. A new set of pretargeted imaging experiments was performed to investigate if a lower dose of PeptoBrush 1 would indeed lead to an improved tumor-tobackground ratio. Pretargeted imaging was performed as previously described with a $72 \mathrm{~h}$ lag time between injection of PeptoBrush 1 (now with $100 \mu \mathrm{g}$ in $100 \mu \mathrm{L}$ of PBS) and administration of $\left[{ }^{111} \mathrm{In}\right] 20(\sim 25 \mathrm{MBq}, 100 \mu \mathrm{L}$, with an apparent $A_{\mathrm{m}}$ of $\left.0.9 \mathrm{GBq} / \mu \mathrm{mol}\right)$. The TCO/Tz ratio at the time of injection was 1.70. Animals were imaged at 2 and $22 \mathrm{~h}$ after administration of $\left[{ }^{111} \mathrm{In}\right] 20$. Visual inspection of the SPECT/ $\mathrm{CT}$ scans showed that the tumor contrast greatly improved, and 

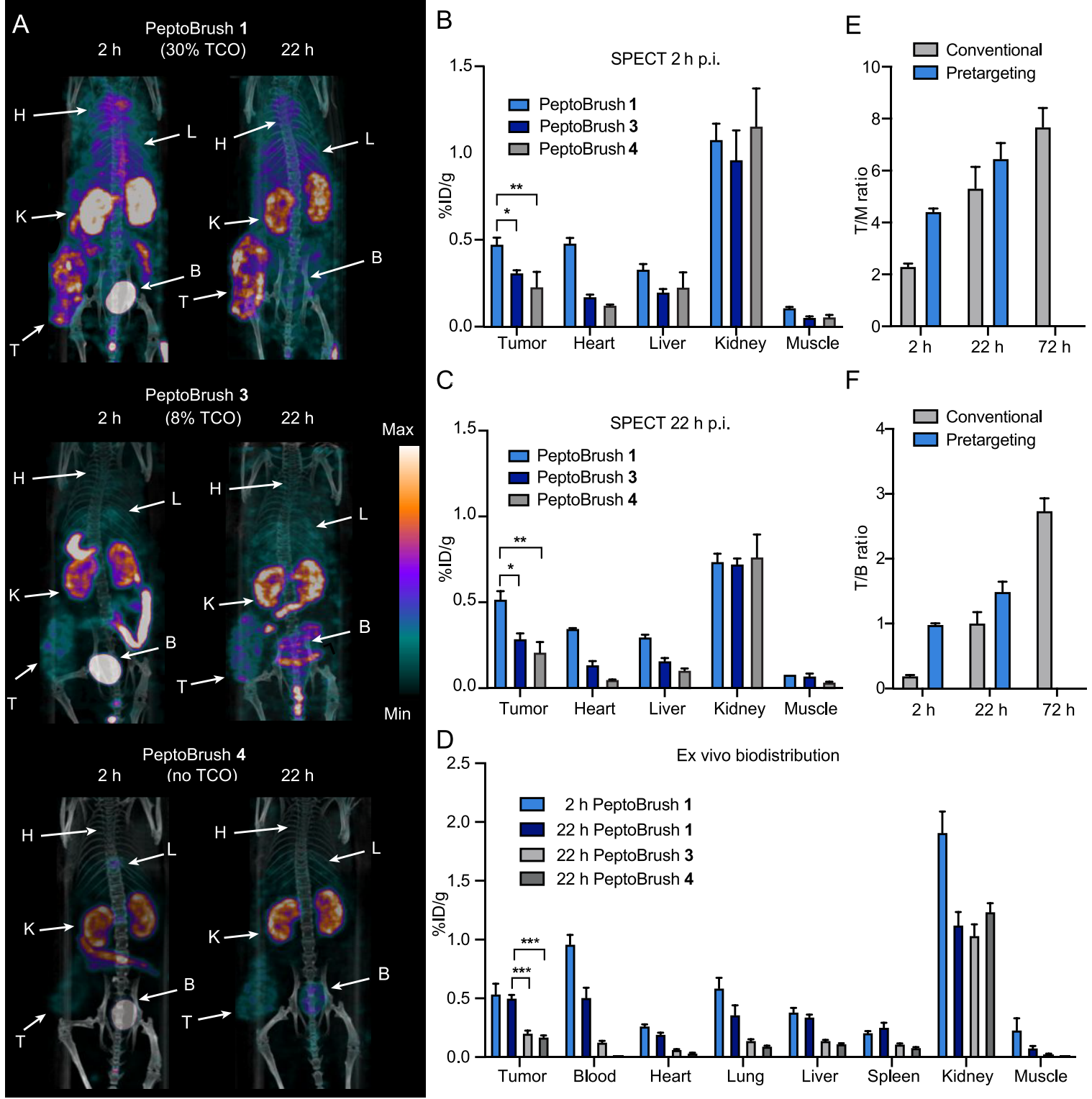

C

$\mathrm{F}$
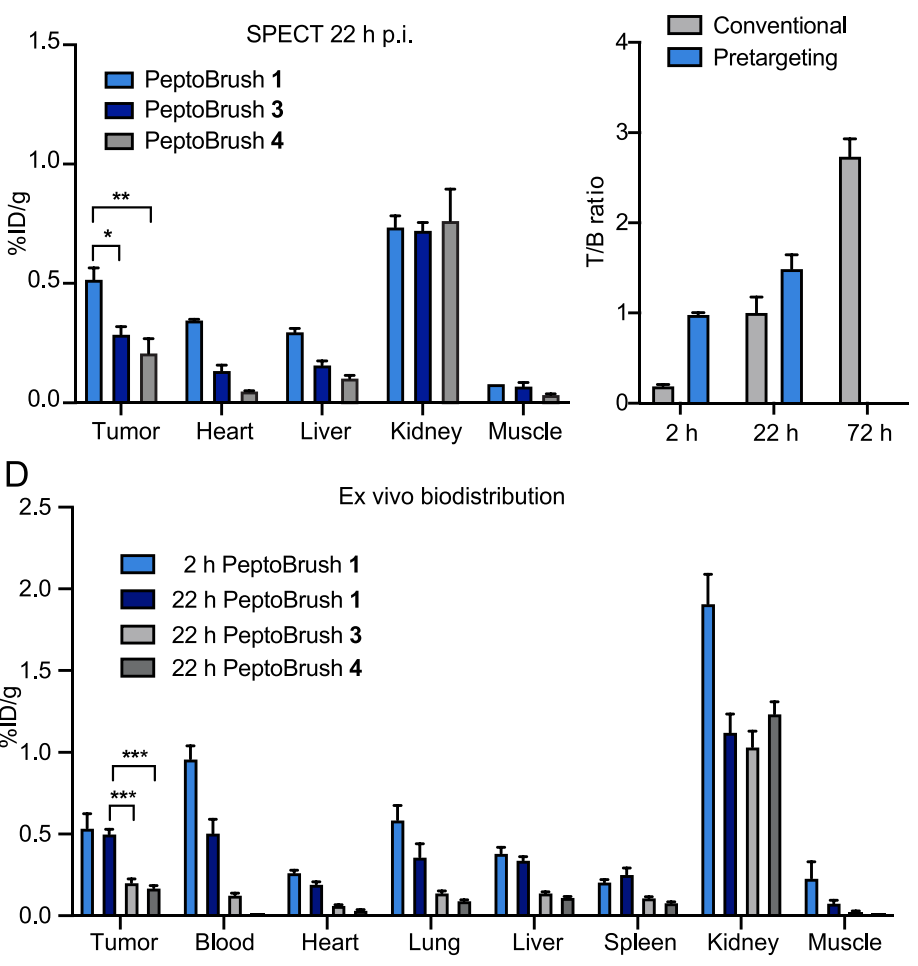

Figure 7. Pretargeted imaging of PeptoBrush $1(100 \mu \mathrm{g})$ and $\left[{ }^{111} \mathrm{In}\right] 20$. (A) Representative SPECT/CT images (maximum intensity projection) of pretargeted imaging 2 and 22 h p.i. PeptoBrush 1, PeptoBrush 3, or PeptoBrush 4 was injected 72 h prior to [111 In] 20, and SPECT/CT imaging was performed at 2 and $22 \mathrm{~h}$ p.i. Each image is scaled between its minimum and maximum pixel intensity; $n=3$ in each group. Data represent mean \pm SEM. Abbreviations: $H=$ heart, $\mathrm{L}=$ liver, $\mathrm{K}=$ Kidney, $\mathrm{B}=$ bladder, and $\mathrm{T}=$ tumor. (B) Image derived mean uptake values $(\%$ $\mathrm{ID} / \mathrm{g}$ ) at $2 \mathrm{~h}$ and $(\mathrm{C})$ at $22 \mathrm{~h}$ p.i. of $\left[{ }^{111} \mathrm{In}\right] 20$ (pretargeted imaging). PeptoBrush 1 was injected $72 \mathrm{~h}$ before $\left[{ }^{111} \mathrm{In}\right] 20$ administration. (D) Ex vivo biodistribution from mice injected with $100 \mu \mathrm{g}$ of PeptoBrush 1, PeptoBrush 3, or PeptoBrush $472 \mathrm{~h}$ before $\left[{ }^{111} \mathrm{In}\right] 20$ administration. (E) Comparison of $\mathrm{T} / \mathrm{M}$ ratios from conventional and pretargeted SPECT imaging. Images and data from conventional imaging with $100 \mu \mathrm{g}\left[{ }^{111} \mathrm{In}\right]$ 21 in SI Figure S16. (F) Comparison of T/B ratios from conventional and pretargeted SPECT imaging. Images and data from conventional imaging with $100 \mu \mathrm{g}\left[{ }^{111} \mathrm{In}\right] 21$ in SI Figure S16. Tumor uptake in (B), (C), and (D) were compared using one-way ANOVA with Tukey's posthoc test; ${ }^{*} p<0.05, * * p<0.01$, and $* * * p<0.001$.

adequate image contrast was already obtained $2 \mathrm{~h}$ p.i. This was in contrast to previous experiments using $1 \mathrm{mg}$ of PeptoBrush 1 (Figure $7 \mathrm{~A}$ versus Figure 5C). Image analysis showed that the mean tumor accumulation was low at $2 \mathrm{~h}$ p.i. $(0.47 \pm 0.04 \% \mathrm{ID} /$ g) (Figure 7B) and, interestingly, did not change significantly during the course of the study with an observed uptake of $0.52 \pm$ $0.05 \% \mathrm{ID} / \mathrm{g}$ at $22 \mathrm{~h}$ p.i. (Figure $7 \mathrm{C}$ ). In general, low uptake values were detected in all examined tissues, with the kidneys and the bladder showing the highest uptake (Figure 7A,D). This observation indicated that $\left[{ }^{111} \mathrm{In}\right] \mathbf{2 0}$ is not any longer primarily reacting with PeptoBrush 1 still circulating in the blood pool, as observed for the $1 \mathrm{mg}$ dose. Instead, ligation between $\left[{ }^{111} \mathrm{In}\right] 20$ and PeptoBrush 1 almost exclusively occurred at the tumor site, and unreacted $\left[{ }^{111} \mathrm{In}\right] \mathbf{2 0}$ was rapidly renally excreted. In contrast to the $1 \mathrm{mg}$ dose, less radiolabeled PeptoBrush 1 is then available for EPR-mediated tumor accumulation, and thus, no massive increase in tumor uptake can be observed over time. However, despite the low tumor uptake, $\mathrm{T} / \mathrm{M}$ and $\mathrm{T} / \mathrm{B}$ ratios were improved compared to the $1 \mathrm{mg}$ study (Figure 7E,F and SI Table S6). For example, the T/B ratio increased by a factor of 5 at the 2 $\mathrm{h}$ time point and by a factor of 1.5 at the $22 \mathrm{~h}$ time point. Consequently, at early time points, the pretargeting strategy resulted in higher imaging contrast compared to conventional imaging $\left(100 \mu \mathrm{g},\left[{ }^{111} \mathrm{In}\right] \mathbf{2 1}\right.$; SI Figure S16). 
Binding Specificity of $\left[{ }^{111}\right.$ In]20 toward PeptoBrushes. To further strengthen that the ligation between $\left[{ }^{111} \mathrm{In}\right] 20$ and TCO moieties of the polymer indeed occurs at the tumor site and that $\left[{ }^{111} \mathrm{In}\right] 20$ is not interacting nonspecifically with the polymeric architecture of the primary targeting agent, additional control experiments using PeptoBrush 3 and PeptoBrush $\mathbf{4}$ were performed using the same pretargeting strategy (100 $\mu \mathrm{g}$ dose of polymer and lag time of $72 \mathrm{~h}$ ). PeptoBrush 3 has a lower TCO loading (8\%) compared to that of PeptoBrush 1 (30\%), whereas PeptoBrush 4 is a polymer without TCO moieties. PeptoBrush 3 and PeptoBrush $\mathbf{4}$ did not result in significant tumor uptake in comparison to PeptoBrush 1 (Figure 7A,D). This observation indicates that the tetrazine ligation takes place in vivo at the tumor site and that the degree of TCO loading affects the performance of the in vivo ligation.

\section{CONCLUSION}

In the present work, we have developed easily accessible and biodegradable TCO-functionalized copolymers, so-called PeptoBrushes, which show EPR-mediated tumor accumulation on the order of approximately $6 \%$ and allow for bioorthogonal chemistry. The core-shell structure adopted by the PeptoBrushes allowed for a high TCO loading, without causing aggregation. Moreover, the high degree of TCO loading resulted in extremely fast reaction kinetics, particularly with a lipophilic Tz. We suggest that the fast second-order rate constants might arise as a result of a combined hydrophobic effect and significant rearrangements of the side chains within each polymer when approximately $25 \%$ of all side chains are functionalized with TCO moieties. These rearrangements create hydrophobic TCO patches consisting of 2-3 TCO moieties, which in turn act as high-affinity binding sites for lipophilic Tz frameworks.

These exciting reaction rate enhancements encouraged us to evaluate PeptoBrush 1, which had the highest TCO loading (30\%) of all developed PeptoBrushes, by both conventional and pretargeted SPECT/CT imaging in tumor-bearing mice. Here, our pretargeting strategy provided adequate image contrast of the tumor already $2 \mathrm{~h}$ after administration of the radiolabeled $\mathrm{Tz}$. In order to further improve the image contrast in the pretargeting strategy, the amount of PeptoBrush 1 still circulating in the blood pool has to be reduced. This is a challenge with respect to pretargeting strategies for both imaging and radionuclide therapy. Future efforts are directed toward finding an appropriate clearing or masking agent to increase the tumor-to-background ratio so that the full potential of PeptoBrush 1 as a primary targeting agent can be unravelled, especially for theranostic approaches. For additional optimization of the pretargeting strategy, we suggest developing a less hydrophilic $\mathrm{Tz}$ imaging agent, compared to the one used in the present work. This would enable higher reaction rates and potentially improve efficiency of the in vivo ligation at the tumor site and thus potentially also give a higher tumor uptake. In summary, PeptoBrush 1 displays excellent properties for a primary targeting agent. Future studies will be centered on increasing the absolute radioactivity concentration in the tumor, lowering background levels further with the aim of utilizing PeptoBrush $\mathbf{1}$ in pretargeted theranostic studies. However, current tumor-to-background levels are sufficient for pretargeted imaging aiming to visualize EPR-mediated tumor uptake of nanomedicines as early as $2 \mathrm{~h}$ after injection of the secondary imaging agent.

\section{MATERIALS AND METHODS}

Materials. Solvents and reagents were purchased from SigmaAldrich or Thermo Fisher Scientific and used as received unless otherwise noted. Tetrahydrofuran (THF) and $n$-hexane were dried over sodium prior to use. Diethyl ether was distilled to remove the stabilizer. Dry $N, N$-dimethylformamide (DMF) over molecular sieves, trifluoroacetic acid (TFA), and hydrobromic acid were purchased from Acros. Prior to use, DMF was degassed by three freeze-pump-thaw cycles to remove residual dimethyl amine. Diphosgene and sarcosine were purchased from Alfa Aesar. Neopentylamine was purchased from TCI Europe. Isopropylamine (Sigma-Aldrich) was dried over sodium hydroxide and fractionally distilled on molecular sieves. L-Glutamic acid 5-benzyl ester was purchased from ORPEGEN Peptide Chemicals $\mathrm{GmbH}$, and 2-chloro-4,6-dimethoxy-1,3,5-triazine was obtained from Carbosynth. (E)-Cyclooct-4-en-1-yl (3-aminopropyl)carbamate (trans-cyclooctene-amine $\mathrm{HCl}$ salt) was purchased from Jena Bioscience $\mathrm{GmbH}$. Deuterated solvents were obtained from Deutero $\mathrm{GmbH}$ (Kastellaun). Milli-Q water (Millipore) with a resistance of $18.2 \mathrm{M} \Omega$ and TOC $<3 \mathrm{ppm}$ was used throughout the experiments. $\left[{ }^{111} \mathrm{In}\right] \mathrm{InCl}_{3}$ in hydrochloric acid was purchased from Mallinckrodt Medical B.V. Compounds 14, 15, 16, 17, 18, and 19 were synthesized as previously described. ${ }^{27,46,47,55,56}$

Methods. ${ }^{1} \mathrm{H}$ NMR $(400 \mathrm{MHz})$ and diffusion-ordered spectra were recorded on a Bruker Avance III HD 400 spectrometer at room temperature. Chemical shifts are reported in parts per million and were referenced to the solvent residual signal. The analysis of the ${ }^{1} \mathrm{H}$ NMR spectra was performed using the software MestReNova v12.0.0 (Mestrelab Research S.L.). Analytical hexafluoroisopropanol (HFIP) SEC was carried out at a flow rate of $0.8 \mathrm{~mL} / \mathrm{min}$ at $40{ }^{\circ} \mathrm{C}$ with $3 \mathrm{~g} / \mathrm{L}$ potassium trifluoroacetate added to the eluent. The SEC system was equipped with a UV detector (Jasco UV-2075 Plus) set at a wavelength of $230 \mathrm{~nm}$ and an RI detector (Jasco RI-2031). Modified silica gel columns (PFG columns, particle size: $7 \mu \mathrm{m}$, porosity: 100 and $1000 \AA$ ) were used. Molecular weights were determined by using a calibration with poly(methyl methacrylate) (PMMA) standards (Polymer Standards Service $\mathrm{GmbH}$ ) and toluene as an internal standard. Degree of polymerization of pSar was determined by calibration of apparent $M_{n}$ against a series of pSar standards characterized by static light scattering to obtain absolute molecular weights. Prior to measurement, the samples were filtered through polytetrafluoroethylene (PTFE) syringe filters with a pore size of $0.2 \mu \mathrm{m}$. The elution diagram was analyzed with WinGPC software (Polymer Standards Service GmbH). Attenuated total reflectance Fourier transform infrared (ATR-FTIR) spectroscopy was performed on a FT/IR-4100 (JASCO Corporation) with an ATR sampling accessory (MIRacleTM, Pike Technologies). The IR spectra were analyzed with the software Spectra Manager version 2.02.05 (JASCO Corporation). For each measurement, 16 scans were performed. For multiangle dynamic light scattering, cylindrical quartz cuvettes (Hellma) were cleaned by dust-free distilled acetone and transferred to a dust-free flow box. Solutions were filtered into the cuvettes through syringe filters. DLS measurements were performed by an apparatus consisting of a Uniphase He/Ne Laser (22.5 mW output power at $\lambda=632.8 \mathrm{~nm}$ ), an ALV/SP125 goniometer with an ALV 5000/E/PCI correlator, and an ALV/High QEAPD Avalanche photodiode detector. All samples were measured at $20{ }^{\circ} \mathrm{C}$. To investigate the aggregation behavior of the particles in human serum, serum pooled from six probands was used. The serum was obtained from the University Medical Center Mainz and filtered through a Millex GS $0.22 \mu \mathrm{m}$ filter (Merck Millipore). The particle solution was filtered through a $0.02 \mu \mathrm{m}$ pore size Anotop filter (Whatman), and the buffer was filtered through a $0.2 \mu \mathrm{m}$ pore size GHP filter (Acrodisc). The following mixtures were prepared: serum/PBS 9:1 and serum/particle solution 9:1 $\left(C_{\text {polymer }}=0.05 \mathrm{~g} / \mathrm{L}\right)$. The cuvettes were incubated for 20 $\mathrm{min}$ at room temperature before measurement. The correlation functions of the particles were fitted using a sum of two exponentials. The $z$-average diffusion coefficient $D_{z}$ was calculated by extrapolating $D_{\text {app }}$ for $q=0$. By formal application of Stokes law, the inverse $z$-average hydrodynamic radius is $R_{\mathrm{h}}=\left\langle R_{\mathrm{h}}-1\right\rangle z-1$. Single-angle DLS and $\zeta$ potential measurements were performed on a Zetasizer Nano ZS 
(Malvern Instruments Ltd., Worcestershire, UK) equipped with a 633 $\mathrm{nm} \mathrm{He}-\mathrm{Ne}$ laser at a fixed scattering angle of $173^{\circ}$ at $25{ }^{\circ} \mathrm{C}$. Three measurements were performed per sample at $1 \mathrm{mg} / \mathrm{mL}$ in $10 \mathrm{mM} \mathrm{NaCl}$ solution as solvent, and size distribution (intensity-weighted) histograms were calculated based on the autocorrelation function of samples, with automated attenuator adjustment and multiple scans (typically 10-15 scans). Disposable polystyrene cuvettes (VWR, Darmstadt, Germany) were used for size measurements and disposable folded capillary cells (Malvern Instruments Ltd., Worcestershire, UK) for $\zeta$ potential measurements. Malvern Zetasizer Software version 7.12 was used to analyze the data. For cryogenic transmission electron microscopy (cryoTEM), $5 \mu \mathrm{L}$ of the polymer solution $(1 \mathrm{mg} / \mathrm{mL}$, in $10 \mathrm{mM} \mathrm{NaCl}$ ) was applied to freshly glow-discharged carbon grids with a copper 200 mesh (Quantfoil Micro Tools GmbH). Excess fluid was removed by direct blotting $(2.5 \mathrm{~s})$, and the grids were individually plunge-frozen in liquid ethane. Grids were cryotransferred in liquid nitrogen using a Gatan cryoholder (model $626 \mathrm{DH}$ ) to a Technai T12 transmission electron microscope equipped with a field emission electron source and operating at $120 \mathrm{kV}$ accelerating voltage. Images were recorded using a TemCam-F416 (TVIPS, Gauting, Germany). Melting points were measured using a Mettler FP62 melting point apparatus at a heating rate of $1{ }^{\circ} \mathrm{C} / \mathrm{min}$. The $C \log D_{7.4}$ values used for the correlation between lipophilicity and reaction kinetics were obtained from Chemicalize software. Thin-layer chromatography (TLC) was carried out using normal phase plates (silica gel 60 coated with fluorescent indicator F254s) from Merck. The fraction of radioactivity on the TLC plates was measured with an instant imager from Packard InstantImager and analyzed by Optiquant software. Analytical high-performance liquid chromatography (HPLC) was performed on a Dionex system connected to a P680A pump, a UVD $170 \mathrm{U}$ detector, and a radiodetector from Scansys Laboratorieteknik. HPLC control and spectra processing were done with Chromeleon 6.8 software.

Synthesis of Homopolymers. Poly( $\gamma$-benzyl-L-glutamic acid) (6). The synthesis of 6 was carried out as previously described. ${ }^{38} \mathrm{~N}$ Carboxyanhydride (NCA) 5 (667 mg, $2.54 \mathrm{mmol}$ ) was transferred into a predried Schlenk tube equipped with a stir bar under nitrogen counter flow and dried under high vacuum for $1 \mathrm{~h}$ prior to solvation in absolute DMF $(6.5 \mathrm{~mL})$. A solution of neopentylamine $(4.45 \mu \mathrm{L}, 0.04 \mathrm{mmol})$ in dry DMF $(1.5 \mathrm{~mL})$ was flushed with argon, before $1 \mathrm{~mL}$ of this solution was added to the solution of $\mathbf{5}$ for initiation of polymerization. The mixture was stirred at $0{ }^{\circ} \mathrm{C}$ and kept at a constant pressure of 1.25 bar of dry nitrogen. Completion of the reaction was confirmed by FTIR spectroscopy (disappearance of the NCA peaks (1855 and 1788 $\left.\left.\mathrm{cm}^{-1}\right)\right)$. Thereafter, trimethylamine $(71 \mu \mathrm{L}, 0.51 \mathrm{mmol})$ and acetic anhydride $(24 \mu \mathrm{L}, 0.25 \mathrm{mmol})$ were added, and the mixture was stirred overnight in order to cap the amine end group. The polymer was precipitated into diethyl ether and centrifuged $\left(4500 \mathrm{rpm}\right.$ at $4{ }^{\circ} \mathrm{C}$ for 15 $\mathrm{min}$ ). After the liquid fraction was discarded, additional diethyl ether was added, and the polymer was resuspended in a sonication bath. The suspension was centrifuged again, and the procedure was repeated. After DMF removal by the resuspension steps, the polymer was dispersed in water and lyophilized to afford $6(489 \mathrm{mg}, 97 \%)$ as fine colorless polymer flakes: ${ }^{1} \mathrm{H}$ NMR $\left(400 \mathrm{MHz}, \mathrm{DMSO}-d_{6} / \mathrm{CDCl}_{3}\right) \delta$ $8.80-7.90(61 \mathrm{H}, \mathrm{br},-\mathrm{CH}-\mathrm{NH}-\mathrm{CO}-)$, 7.35-7.10 (515H (5n), br, $\left.-\mathrm{CH}_{2}-\mathrm{C}_{6} \mathrm{H}_{5}\right), 5.15-4.80\left(200 \mathrm{H}(2 \mathrm{n}), \mathrm{br},-\mathrm{O}-\mathrm{CH}_{2}-\mathrm{C}_{6} \mathrm{H}_{5}\right), 4.25-$ $3.65(91 \mathrm{H}(1 \mathrm{n}), \mathrm{br},-\mathrm{CO}-\mathrm{CH}-\mathrm{NH}-), 2.75-1.70(302 \mathrm{H}(4 \mathrm{n}), \mathrm{m}$, $\left.-\mathrm{CH}_{2}-\mathbf{C H}_{2}-\right), 0.86\left(9 \mathrm{H}, \mathrm{s}, \mathrm{CH}_{2}-\mathrm{C}\left(\mathbf{C H}_{3}\right)_{3}\right)$. SEC in HFIP (vs PMMA standards): $M_{n}=21.1 \mathrm{~kg} / \mathrm{mol}, \emptyset=1.13$.

Polyglutamic Acid (7). Deprotection of 6 was carried out according to the literature. ${ }^{57}$ The pGlu $(\mathrm{OBn})_{100}(233 \mathrm{mg})$ was dissolved in TFA $(2.5 \mathrm{~mL})$ in a Schlenk tube equipped with a stir bar. The solution was stirred for $10 \mathrm{~min}$, and thereafter $48 \% \mathrm{v} / \mathrm{v} \mathrm{HBr}(240 \mu \mathrm{L}, 2$ equiv per carboxyl group) was added dropwise and the mixture was stirred at room temperature overnight. The next day, the solution was precipitated into cold diethyl ether and centrifuged (4500 rpm at 4 ${ }^{\circ} \mathrm{C}$ for $15 \mathrm{~min}$ ). After the liquid fraction was discarded, additional diethyl ether was added and the polymer was resuspended in a sonication bath. The suspension was centrifuged again, and the procedure was repeated. Remaining diethyl ether was removed under a stream of nitrogen to afford 7 (134 mg, 97\%) as a colorless solid: ${ }^{1} \mathrm{H}$ NMR (400 MHz, $\left.\mathrm{D}_{2} \mathrm{O} / \mathrm{NaOD}\right) \delta 4.15-4.00(100 \mathrm{H}(\mathrm{n}), \mathrm{m},-\mathrm{HN}-$ CH-CO- ), 2.10-1.95 (217H (2n), m, $\left.-\mathbf{C H}_{2}-\mathrm{COOH}\right), 1.90-1.60$ $\left(221 \mathrm{H}(2 \mathrm{n}), \mathrm{m}, \mathrm{CH}-\mathrm{CH}_{2}-\mathrm{CH}_{2}-\right), 0.64\left(9 \mathrm{H}, \mathrm{s},-\mathrm{C}\left(\mathrm{CH}_{3}\right)_{3}\right)$.

Polysarcosine (12). pSar (12) was synthesized in a similar fashion as previously described but with minor adjustments due to the volatile nature of the initiator. ${ }^{38}$ Sar-NCA $13(714 \mathrm{mg}, 11.0 \mathrm{mmol})$ was transferred into a predried Schlenk tube equipped with a stir bar under nitrogen counter flow and dried under high vacuum for $1 \mathrm{~h}$ prior to reaction. NCA 13 was dissolved in absolute DMF $(10 \mathrm{~mL})$, and $93.7 \mu \mathrm{L}$ of a solution of isoproylamine $(0.2 \mathrm{~mL}$ in $1.8 \mathrm{~mL}$ of DMF) was added for initiation with an Eppendorf pipet against nitrogen counter flow. The solution was stirred overnight at room temperature and kept at a constant pressure of 1.25 bar of dry nitrogen via the Schlenk line. Completion of the reaction was confirmed by FTIR spectroscopy (disappearance of the NCA peaks (1853 and $\left.1786 \mathrm{~cm}^{-1}\right)$ ). The polymer was precipitated into diethyl ether and centrifuged (4500 rpm at $4{ }^{\circ} \mathrm{C}$ for $\left.10 \mathrm{~min}\right)$. After the liquid fraction was discarded, additional diethyl ether was added and the polymer was resuspended in a sonication bath. The suspension was centrifuged again, and the procedure was repeated. After DMF removal by the resuspension steps, the polymer was dissolved in water and lyophilized to afford 12 (436 $\mathrm{mg}, 98 \%)$ as a fluffy colorless polymer: ${ }^{1} \mathrm{H}$ NMR $\left(400 \mathrm{MHz}, \mathrm{DMSO}-d_{6}\right)$ $\delta$ 4.70-3.70 (194H (2n), br, $\left.-\mathrm{NCH}_{3}-\mathrm{CH}_{2}-\mathrm{CO}-\right)$, 3.10-2.60 $\left(317 \mathrm{H}(3 \mathrm{n}), \mathrm{br},-\mathrm{NCH}_{3}\right), 1.10-1.00\left(6 \mathrm{H}, \mathrm{m},-\mathrm{CH}\left(\mathrm{CH}_{3}\right)_{2}\right)$. SEC in HFIP (vs PMMA standards): $M_{n}=22.2 \mathrm{~kg} / \mathrm{mol}, Ð=1.10$. Degree of polymerization was determined to be 82 by calibration of apparent $M_{n}$ against a series of pSar standards characterized by static light scattering to obtain absolute molecular weights. ${ }^{58}$

TCO Functionalization. 4-(4,6-Dimethoxy-1,3,5-triazin-2-yl)-4methyl Morpholinium Chloride. 4-(4,6-Dimethoxy-1,3,5-triazin-2-yl)4-methyl morpholinium chloride (DMTMM Cl) was freshly prepared according to literature. ${ }^{59} \mathrm{~N}$-Methyl morpholine $(1.73 \mathrm{~g}, 17.1 \mathrm{mmol})$ was added to a solution of 2-chloro-4,6-dimethoxy-1,3,5-triazine (3.00 $\mathrm{g}, 17.1 \mathrm{mmol})$ in dry THF $(100 \mathrm{~mL})$. The mixture was stirred at room temperature under nitrogen atmosphere for $1 \mathrm{~h}$. The precipitate was collected by filtration under a nitrogen atmosphere. After $2 \mathrm{~h}$ of constant nitrogen flow through the precipitate and $2 \mathrm{~h}$ under high vacuum, DMTMM Cl (3.44 g, 73\%) was afforded as colorless crystals, which were aliquoted into $2 \mathrm{~mL}$ Eppendorf vials and stored at $-20{ }^{\circ} \mathrm{C}$ : ${ }^{1} \mathrm{H}$ NMR (400 MHz, DMSO- $\left.d_{6}\right) \delta 4.60-4.50\left(2 \mathrm{H}, \mathrm{d}, \mathrm{br},-\mathrm{N}^{+} \mathrm{CH}_{2}-\right.$ ), 4.10-4.00 (8H, m, $-\mathrm{OCH}_{3}$ and $\left.\mathrm{CH}_{3} \mathrm{~N}^{+} \mathrm{CH}_{2}\right), 3.65-3.90(4 \mathrm{H}, \mathrm{m}$, $\left.-\mathrm{OCH}_{2}-\right), 3.45\left(3 \mathrm{H}, \mathrm{s},-\mathrm{N}^{+} \mathrm{CH}_{3}\right)$. The procedure for TCO functionalization toward PeptoBrush 9 is described below. PeptoBrushes 10 and 11 were synthesized according to the same procedure in 34 and $36 \%$ yields, respectively.

PeptoBrush 9. The deprotected and lyophilized $\mathrm{p}\left(\mathrm{Glu}_{100}\right)(57.6 \mathrm{mg}$ $0.409 \mathrm{mmol} \mathrm{COOH}),((E)$-cyclooct-4-en-1-yl(3-aminopropyl)carbamate) (32.2 mg, $0.12 \mathrm{mmol}, 0.3$ equiv) and $\mathrm{NaHCO}_{3}(172 \mathrm{mg}$, $2.04 \mathrm{mmol}, 5$ equiv) were dissolved in MP water $(6 \mathrm{~mL})$ and DMSO $(1.2 \mathrm{~mL})$. The mixture was stirred at room temperature for $30 \mathrm{~min}$ before DMTMM Cl salt ( $113.0 \mathrm{mg}, 0.409 \mathrm{mmol}, 1$ equiv) was added, and the solution was stirred at room temperature under a nitrogen atmosphere for $24 \mathrm{~h}$. After $24 \mathrm{~h}$, additional DMTMM Cl (113.0 mg, 0.409 mmol, 1 equiv) was added and the mixture was stirred for $24 \mathrm{~h}$. The adduct was purified by dialysis against a $6-8 \mathrm{kDa}$ molecular weight cutoff (MWCO) regenerated cellulose membrane for 1 week with daily change of water. After lyophilization, PeptoBrush 9 (56.5 mg, 74\%) was obtained as a fluffy colorless powder: ${ }^{1} \mathrm{H}$ NMR $\left(400 \mathrm{MHz}, \mathrm{D}_{2} \mathrm{O}\right) \delta$ $5.60-5.20(60 \mathrm{H}(2 \mathrm{~m}), \mathrm{m}, \mathbf{C H}=\mathbf{C H}), 4.40-3.80(206 \mathrm{H}(m+n)$, $-\mathrm{HN}-\mathrm{CH}-\mathrm{CO}-$ and $\left.\mathrm{O}-\mathrm{CH}-\left(\mathrm{CH}_{2}\right)_{2}\right), 3.20-2.70(156 \mathrm{H}, \mathrm{d}, \mathrm{br})$, $2.40-1.60(1037 \mathrm{H}, \mathrm{br}), 1.60-1.20(187 \mathrm{H} \mathrm{br}), 0.71-0.62(9 \mathrm{H}, \mathrm{s}, \mathrm{br}$ $\left.-\mathrm{C}\left(\mathrm{CH}_{3}\right)_{3}\right)$.

Polysarcosinylation. The procedure for pSar grafting of PeptoBrush 9 to afford PeptoBrush 1 is described below. PeptoBrushes 2 ( $25 \%$ yield), 3 ( $20 \%$ yield), and 4 ( $30 \%$ yield) were synthesized according to the same procedure from PeptoBrushes $\mathbf{1 0}$ and $\mathbf{1 1}$ and the pGlu backbone 4, respectively.

PeptoBrush 1. To PeptoBrush 9 ( $5.70 \mathrm{mg}, 0.03 \mathrm{mmol}, 1$ equiv Glu) were added 12 (91.0 mg, $0.02 \mathrm{mmol}, 0.5$ equiv (per Glu)) and 
$\mathrm{NaHCO}_{3}(26.0 \mathrm{mg}, 0.31 \mathrm{mmol}, 10$ equiv). The reagents were dissolved in MP water $(2 \mathrm{~mL})$ and DMSO $(0.4 \mathrm{~mL})$ and stirred at room temperature for $30 \mathrm{~min}$. DMTMM Cl ( $17.0 \mathrm{mg}, 0.06 \mathrm{mmol}, 2$ equiv) was added, and the mixture was stirred overnight. After 24 and $48 \mathrm{~h}$, additional fresh DMTMM Cl (17 mg, $0.0613 \mathrm{mmol}, 2$ equiv) was added, and SEC analysis (sampling of reaction solutions $(5 \mu \mathrm{L})$ added to toluene $(10 \mu \mathrm{L})$ in HFIP $(1 \mathrm{~mL})$, filtered through a $450 \mathrm{~nm}$ PTFE filter as sample preparation) revealed increasing brush size after the first but not the second successive step, which indicated close to saturated functionalization. The solution was thereafter transferred into Vivaspin 2 centrifugation filters with a molecular weight cutoff of $20 \mathrm{kDa}$ in two steps, diluted to a total volume of $2 \mathrm{~mL}$ with MP water, and spun $2 \times 20$ $\mathrm{min}$. The filtrates were removed after every centrifugation step. After concentration, the filters were again diluted to a total volume of $2 \mathrm{~mL}$ with MP water and centrifuged as previously described. The procedure was repeated six times until SEC analysis revealed no significant amounts of remaining pSar homopolymers. After lyophilization, the purified brush polymer (18 $\mathrm{mg}, 39 \%$ referred to the brush species) was afforded: ${ }^{1} \mathrm{H}$ NMR $\left(400 \mathrm{MHz}, \mathrm{D}_{2} \mathrm{O}\right) \delta 5.80-5.40(18 \mathrm{H}(2 \mathrm{~m}), \mathrm{m}$, $\mathbf{C H}=\mathbf{C H}), \quad 4.70-3.80\left(3531 \mathrm{H}(1 n+1 m+164 k), \mathrm{HN}-\mathbf{C H}_{2}-\mathrm{CO}+\right.$ $\left.\mathrm{HN}-\mathrm{CH}-\mathrm{CO}+\mathrm{O}-\mathrm{CH}-\left(\mathrm{CH}_{2}\right)_{2}\right), 3.40-2.80(5200 \mathrm{H}(246 \mathrm{k}), \mathrm{m}$, $\left.\mathrm{N}-\mathrm{CH}_{3}\right), 2.70-1.80(303 \mathrm{H}, \mathrm{br}), 1.80-1.40(45 \mathrm{H}, \mathrm{br}), 1.20-1.10$ $\left(109 \mathrm{H}(6 \mathrm{k}), \mathrm{m},-\mathrm{CH}\left(\mathbf{C H}_{3}\right)_{2}\right), 0.85\left(9 \mathrm{H}, \mathrm{s},-\mathrm{C}\left(\mathbf{C H}_{3}\right)_{3}\right)$.

Kinetic Studies. Reaction kinetics of the TCO moieties in PeptoBrushes 1-3 and TCO control compound 16 with fluorogenic turn-on $\mathrm{Tz}$ derivatives 14 and $\mathbf{1 5}$ were determined by pseudo-firstorder measurements in PBS ( $\mathrm{pH} 7.4$ ) at $37.0 \pm 0.1{ }^{\circ} \mathrm{C}$ following the increase of fluorescence at $>400 \mathrm{~nm}$. Reaction kinetics of the TCO moieties of PeptoBrushes 1 and 16 with Tz derivatives 18 and 19 were determined under the same conditions following the decrease of tetrazine absorbance at $535 \mathrm{~nm}$. Measurements were performed using a SX20 stopped-flow photometer (Applied Photophysics, UK) equipped with either a $360 \mathrm{~nm}$ LED light source and a photomultiplier-type R374 in combination with a $400 \mathrm{~nm}$ long-pass filter for fluorescence measurements or a $535 \mathrm{~nm}$ LED light source and a photomultipliertype R928 for absorbance measurements. Twenty millimolar stock solutions of 14 and 15 in DMSO- $d_{6}$ were diluted in PBS (1:40000 or $1: 200000)$, resulting in 500 and $100 \mathrm{nM}$ solutions, respectively. For fluorescence measurements, solutions of PeptoBrushes 1-3 and 16 were prepared to yield TCO concentrations exceeding $10 \mu \mathrm{M}$ to ensure pseudo-first-order conditions. Tz and TCO solutions were mixed 1:1 (v/v) during measurements, resulting in 250 or $50 \mathrm{nM}$ solution of 14 or 15 and TCO concentrations of $\geq 5 \mu \mathrm{M}$. In the case of absorbance measurements, solutions of Peptobrushes 1 and 16 were prepared to yield TCO concentrations exceeding $500 \mu \mathrm{M}$. Tz solution concentrations were adjusted to $50 \mu \mathrm{M}$.

Reaction kinetics under biological conditions were measured in Gibco Fluorobrite DMEM including 10\% fetal bovine serum at $37.0 \pm$ $0.1{ }^{\circ} \mathrm{C}$. The used concentrations, observed rate constants, and calculated second-order rate constants are shown in SI Tables S1 and S2.

Determination of the Number of Reactive TCO Units per Polymer. A solution of PeptoBrush 1 in DMSO $(1 \mathrm{~mL}, 8 \mu \mathrm{M})$ was mixed in a cuvette with an excess (1.5 equiv) of a solution of 3,6dimethyltetrazine $(17,98.7 \mu \mathrm{M})$, and the absorption at $535 \mathrm{~nm}$ was monitored using a Thermo Scientific NanoDrop One ${ }^{\mathrm{C}} \mathrm{UV}$-vis spectrophotometer until a constant value was reached. Subsequently, another half equiv of $\mathrm{Tz}$ was added, and the measurement was repeated. This procedure was carried out an additional three times (five data points in total). The Tz concentration was plotted against the measured absorption, and the linear regression was extrapolated to intersect the $x$ axis, with the intersection point equating to the effective TCO concentration (SI Table S3).

Coarse-Grained Computer Simulations. The coarse-grained computer simulations were based on a standard spring-bead model with FENE bonds and nonbonded purely repulsive Lennard-Jones-type (i.e., WCA-type) interactions between beads. The brushes have a regular architecture and consist of a backbone chain with 101 monomers (beads) and 25 side chains with 80 monomers each. TCO units are distributed evenly on the backbone with the constraint that monomers that serve as starting points for side chains cannot carry a TCO unit. Monomers carrying a TCO unit have additional attractive interactions with a potential depth of 1.5 thermal energy units. The detailed equations for the potentials are given in the SI. Molecular dynamics simulations were performed at constant temperature using the Verlet algorithm with a time step of $\Delta \tau=0.001 \tau$ in Lennard-Jones time units $\tau$. After an equilibration period of at least $1 \times 10^{5} \tau$ (corresponding to 100 Mio time steps), data were collected over another $5 \times 10^{5} \tau$ (500 Mio time steps).

Radiolabeling of Tetrazine. $\mathrm{Tz}\left(\left[{ }^{111} \mathrm{In}\right] 20\right)$ was prepared as previously described with minor modifications. ${ }^{27}$ For the radiolabeling, $\left.{ }^{[111} \mathrm{In}\right] \mathrm{InCl}_{3}(300-1000 \mu \mathrm{L}, 306-647 \mathrm{MBq})$ was added to a solution of $1 \mathrm{M} \mathrm{NH}_{4} \mathrm{OAc} \mathrm{pH} 5.0(150-500 \mu \mathrm{L})$ and DOTA-Tz precursor $19(0.1$ $\mathrm{mg}, 78 \mathrm{nmol}, 50 \mu \mathrm{L}$ from stock solution in metal-free water). Depending on the amount of $\left[{ }^{111} \mathrm{In}\right] \mathrm{InCl}_{3}$ used for the labeling, half of the volume $1 \mathrm{M} \mathrm{NH}_{4} \mathrm{OAc} \mathrm{pH} 5.0$ was needed. The mixture was heated at $60{ }^{\circ} \mathrm{C}$ for $5 \mathrm{~min}$, before $13 \mathrm{mM}$ gentisic acid in saline $(29.3 \mu \mathrm{L})$ and $10 \mathrm{mM}$ DTPA in PBS $(5 \mu \mathrm{L})$ were added. The mixture was heated at 60 ${ }^{\circ} \mathrm{C}$ for 5 additional minutes. Analysis was performed by radio-TLC with $200 \mathrm{mM}$ EDTA in MQ water as eluent and with radio-HPLC on a Yarra $3 \mu \mathrm{m}$ SEC-2000 LC column $(300 \times 7.8 \mathrm{~mm})$ using $\mathrm{Na}_{2} \mathrm{HPO}_{4} /$ $\mathrm{NaH}_{2} \mathrm{PO}_{4}$ buffer ( $\mathrm{pH}$ 7.0) with $0.01 \% \mathrm{NaN}_{3}$ as eluent. [ $\left.{ }^{111} \mathrm{In}\right] 20$ was afforded in a radiochemical yield of $94 \pm 5 \%(n=7)$, which was determined by radio-TLC. Radio-TLC and radio-HPLC chromatograms are shown in the SI. Afterward, the concentration of the solution was adjusted with additional DOTA-functionalized $\mathrm{Tz} 19$ to get a concentration of $11 \mathrm{nmol} / 100 \mu \mathrm{L}$ for the injections.

Radiolabeling of PeptoBrush 1. $\left[{ }^{111} \mathrm{In}\right] 20$ was diluted with PBS (300-100 $\mu \mathrm{L}$; the volume for dilution depended on the total volume of the isolated $\left[{ }^{111} \mathrm{In}\right] \mathbf{2 0}$ to reach a $\mathrm{pH}$ of approximately 7 , which is used for the labeling of the polymer; at $\mathrm{pH}<4.5$, the polymer tends to decompose), and PeptoBrush 1 ( $2 \mathrm{mg}$ ) dissolved in PBS (200-500 $\mu \mathrm{L}$ ) was added. After $10 \mathrm{~min}$ at room temperature, the reaction was analyzed by radio-HPLC on a Yarra $3 \mu \mathrm{m}$ SEC-2000 LC column $(300 \times$ $7.8 \mathrm{~mm}$ ) using $\mathrm{Na}_{2} \mathrm{HPO}_{4} / \mathrm{NaH}_{2} \mathrm{PO}_{4}$ buffer $(\mathrm{pH} 7.0)$ with $0.01 \% \mathrm{NaN}_{3}$ as eluent. [ $\left.{ }^{111} \mathrm{In}\right] 21$ was afforded in a radiochemical purity (RCP) of $76-99 \%$, as determined by radio-HPLC. In contrast, radio-TLC measurements indicated that a RCP of $>99 \%$ was achieved. The observed difference was attributed to the fact that in our HPLC method, ${ }^{111} \mathrm{In}^{3+}$ tends to get released from the chelator (for both [ $\left.{ }^{111} \mathrm{In}\right] 20$ and $\left.\left[{ }^{111} \mathrm{In}\right] 21\right)$. Afterward, the concentration of PeptoBrush $\mathbf{1}$ in the labeling solution was adjusted to get the correct dose per $100 \mu \mathrm{L}$ for injections.

Animal Model. All animal studies were approved by the Danish Animal Welfare Council, Ministry of Justice. Five week old female Balb/ c mice (Charles River) were allowed to acclimatize for 1 week with access to water and chow ad libitum. Mouse colon carcinoma cell line (CT26; obtained from ATCC) was cultured in RPMI-1640 medium supplemented with $10 \%$ fetal bovine serum and $1 \%$ penicillinstreptomycin at $37{ }^{\circ} \mathrm{C}$ and $5 \% \mathrm{CO}_{2}$. Cells were harvested by trypsinization at a confluence of $80-90 \%$, and subcutaneous tumors were established in the left flank of the animals by inoculation of $\sim 3 \times$ $10^{5} \mathrm{CT} 26$ cells resuspended in growth media $(100 \mu \mathrm{L})$ and allowed to grow for 2 weeks. Tumors were measured using a caliper, and the volume was calculated using the formula, volume $=1 / 2$ (length $\times$ width ${ }^{2}$ ).

SPECT/CT Imaging. Animals were imaged with a small animal SPECT/CT scanner (nanoSPECT/CT, Mediso) with four detector heads. CT scans were acquired following a semicircular multifield of view method in Nucline Software: 720 projections, $35 \mathrm{kVp}, 980 \mu \mathrm{A}, 450$ ms, 1:4 binning and reconstructed using small voxel size, thin slice thickness, and cosine as filter type. SPECT images were acquired using Nucline Software between 50.000 and 100.000; counts were achieved for each projection; photopeaks were set to primary peak of $245.4 \mathrm{keV}$ (20\% full width) and secondary peak of $171.3 \mathrm{keV}$ ( $20 \%$ full width). After the last scan, all animals were euthanized by cervical dislocation. The radioactivity, in two tubes containing different amounts of indium111, was measured in the dose calibrator, and the tubes were SPECT/ CT scan and used as external standards to validate quantification. SPECT images were reconstructed using Tera-Tomo 3D SPECT 
reconstruction software. The mean \% ID/g in the tumor, muscle, heart, liver, and kidney was extracted by manually drawing $2 \mathrm{D}$ regions of interest that was interpolated to a $3 \mathrm{D}$ volume of interest using VivoQuant software.

Conventional Imaging Studies. Groups of four tumor-bearing animals (tumor volumes between 150 and $500 \mathrm{~mm}^{3}$ ) were administered [ $\left.{ }^{111} \mathrm{In}\right] 21\left(100 \mu \mathrm{g}, \sim 10 \mathrm{MBq}\right.$, apparent $A_{\mathrm{s}}$ of $114 \mathrm{MBq} /$ $\mathrm{mg} ; 500 \mu \mathrm{g}, \sim 40 \mathrm{MBq}$, apparent $A_{\mathrm{s}}$ of $69 \mathrm{MBq} / \mathrm{mg} ; 1000 \mu \mathrm{g}, \sim 50 \mathrm{MBq}$, apparent $A_{\mathrm{s}}$ of $109 \mathrm{MBq} / \mathrm{mg}$ ) via the tail vein. The animals were anesthetized by breathing sevoflurane and SPECT/CT scanned 2, 22, and $72 \mathrm{~h}$ p.i. of $\left[{ }^{111} \mathrm{In}\right] \mathbf{2 1}$.

Pretargeted Imaging Studies. Three days before the study started, tumor-bearing animals $(n=4)$ were injected with either 100 , 500, or $1000 \mu \mathrm{g}$ of PeptoBrush 1 in $100 \mu \mathrm{L}$ of PBS (0.1 M) in the tail vein. On the day of the scan, the animals (tumor volumes between 150 and $\left.500 \mathrm{~mm}^{3}\right)$ were administered $\left.{ }^{111} \mathrm{In}\right] 20(100 \mu \mathrm{g}, \sim 25 \mathrm{MBq}, 100 \mu \mathrm{L}$, with an apparent $A_{\mathrm{m}}$ of $0.9 \mathrm{GBq} / \mu \mathrm{mol} ; 500 \mu \mathrm{g}, \sim 15 \mathrm{MBq}, 100 \mu \mathrm{L}$, with an apparent $A_{\mathrm{m}}$ of $3.0 \mathrm{GBq} / \mu \mathrm{mol} ; 1000 \mu \mathrm{g}, \sim 50 \mathrm{MBq}, 95 \mu \mathrm{L}$, with an apparent $A_{\mathrm{m}}$ of $5.4 \mathrm{GBq} / \mu \mathrm{mol}$ ) via the tail vein. The animals were anesthetized by breathing sevoflurane and SPECT/CT scanned 2 and $22 \mathrm{~h}$ p.i. of the ${ }^{111}$ In-labeled Tz.

Ex Vivo Biodistribution. Dose Optimization. CT26 tumorbearing mice were divided into four groups based on their tumor volume (mean tumor volume of $=130 \pm 33 \mathrm{~mm}^{3}, n=4$ in each group) and were administered with either $50,100,250$, or $500 \mu \mathrm{g}$ of PeptoBrush 1. After $72 \mathrm{~h}$ lag time, mice were administered with [ $\left.{ }^{111} \mathrm{In}\right]$ $20\left(\sim 20 \mathrm{MBq}, 100 \mu \mathrm{L}\right.$, apparent $\left.A_{\mathrm{m}}=1.6 \mathrm{GBq} / \mu \mathrm{mol}\right)$ through the tail vein. After $2 \mathrm{~h}$, the animals were euthanized, tissue resected and weighed, and the radioactivity measured on a gamma counter (Wizard2, PerkinElmer). Data were corrected for decay, tissue weight, and injected amount of radioactivity.

Optimization of Lag Time. CT26 tumor-bearing animals were divided into groups based on their tumor volume (mean tumor volume of $=87 \pm 39 \mathrm{~mm}^{3}, n=3$ mice per time point) and were administered with either 100 or $500 \mu \mathrm{g}$ of $\left[{ }^{111} \mathrm{In}\right] 21(100 \mu \mathrm{g}, \sim 10 \mathrm{MBq}, 100 \mu \mathrm{L}$, apparent $A_{\mathrm{s}}=101 \mathrm{MBq} / \mathrm{mg} ; 500 \mu \mathrm{g}, \sim 8 \mathrm{MBq}, 100 \mu \mathrm{L}$, apparent $A_{\mathrm{s}}=13$ $\mathrm{MBq} / \mathrm{mg}$ ) via the tail vein. At the time points of $2,22,48,72,96,120$, and $144 \mathrm{~h}$, groups were terminated by euthanizing the animals, and the tumor, blood, liver, and kidney were resected, weighed, and the radioactivity measured on a gamma counter. Data were corrected for decay, tissue weight, and the injected amount of radioactivity.

Tissue Uptake of PeptoBrush 1, Peptobrush 3, and PeptoBrush 4. CT26 tumor-bearing animals were divided into groups based on their tumor volume (mean tumor volume of $=180 \pm 72 \mathrm{~mm}^{3}, n=3$ in each group) and were administered with either 100 or $500 \mu \mathrm{g}$ of PeptoBrush 1, PeptoBrush 3, or PeptoBrush 4. After $72 \mathrm{~h}$, mice were administered with [ $\left.{ }^{111} \mathrm{In}\right] 20\left(100 \mu \mathrm{g}, \sim 25 \mathrm{MBq}, 100 \mu \mathrm{L}\right.$, with an apparent $A_{\mathrm{m}}$ of 0.9 $\mathrm{GBq} / \mu \mathrm{mol} ; 500 \mu \mathrm{g}, \sim 13 \mathrm{MBq}$, apparent $\left.A_{\mathrm{m}}=3.0 \mathrm{GBq} / \mu \mathrm{mol}\right)$ through the tail vein. They were euthanized $22 \mathrm{~h}$ p.i. (or subsequently following the $22 \mathrm{~h}$ scan), tissue was resected and weighed, and the radioactivity measured on a gamma counter. Data were corrected for decay, tissue weight, and injected amount of radioactivity.

Statistical Analysis. Statistical analysis was performed in GraphPad Prism 8. The tumor uptake achieved using different PeproBrushes as primary targeting agents were compared with one-way ANOVA with Tukey's posthoc test. All statistical results were considered significant when the $p$ value was $<0.05$.

\section{ASSOCIATED CONTENT}

\section{Supporting Information}

The Supporting Information is available free of charge at https://pubs.acs.org/doi/10.1021/acsnano.9b06905.

Theoretical analysis of reaction rate constants for the tetrazine ligation based on the Smoluchowski theory, synthetic procedures of 4, 5, and 13, PeptoBrush characterization of 2,3 , and 4, kinetic measurements, determination of the number of reactive TCO moieties per polymer, stability of PeptoBrush 1 in human serum, radiochemistry, additional biodistribution data, and analytic data for the polymer synthesis (PDF)

\section{AUTHOR INFORMATION}

\section{Corresponding Authors}

*Tel: +45 3533 6624. Fax: +45 3533 6041. E-mail: matthias. herth@sund.ku.dk.

*Tel: +45 2725 8614. E-mail: andreas.kjaer@regionh.dk.

*Tel: +49 613139 26256. Fax: +49 613139 24778. E-mail: barz@uni-mainz.de.

ORCID

Marc S. Robillard: 0000-0002-3690-2087

Jesper L. Kristensen: 0000-0002-5613-1267

Hannes Mikula: 0000-0002-9218-9722

Matthias Barz: 0000-0002-1749-9034

Andreas Kjær: 0000-0002-2706-5547

Matthias M. Herth: 0000-0002-7788-513X

Author Contributions

E.J.L.S., J.T.J., and K.J. contributed equally to the work.

Notes

The authors declare no competing financial interest.

\section{ACKNOWLEDGMENTS}

This project has received funding from the European Union's EU Framework Programme for Research and Innovation Horizon 2020, under Grant Agreement No. 668532. A.K. and M.H. have received funding from the European Union's EU Framework Programme for Research and Innovation Horizon 2020 (Grant Agreement No. 670261), the Lundbeck Foundation, the Novo Nordisk Foundation, the Innovation Fund Denmark, and the Research Council for Independent Research. M.B. and F.S. acknowledge funding from the SFB 1066-2. K.J. would like to thank the Max Planck Graduate Center (MPGC) for financial support.

\section{REFERENCES}

(1) Shi, J.; Kantoff, P. W.; Wooster, R.; Farokhzad, O. C. Cancer Nanomedicine: Progress, Challenges and Opportunities. Nat. Rev. Cancer 2017, 17, 20-37.

(2) Lammers, T.; Kiessling, F.; Hennink, W. E.; Storm, G. Drug Targeting to Tumors: Principles, Pitfalls and (Pre-) Clinical Progress. J. Controlled Release 2012, 161, 175-187.

(3) Matsumura, Y.; Maeda, H. A New Concept for Macromolecular Therapeutics in Cancer Chemotherapy: Mechanism of Tumoritropic Accumulation of Proteins and the Antitumor Agent Smancs. Cancer Res. 1986, 46, 6387-6392.

(4) Ribatti, D.; Nico, B.; Crivellato, E.; Vacca, A. The Structure of the Vascular Network of Tumors. Cancer Lett. 2007, 248, 18-23.

(5) Fang, J.; Nakamura, H.; Maeda, H. The EPR Effect: Unique Features of Tumor Blood Vessels for Drug Delivery, Factors Involved, and Limitations and Augmentation of the Effect. Adv. Drug Delivery Rev. 2011, 63, 136-151.

(6) Dewhirst, M. W.; Secomb, T. W. Transport of Drugs From Blood Vessels to Tumour Tissue. Nat. Rev. Cancer 2017, 17, 738-750.

(7) Lee, H.; Shields, A. F.; Siegel, B. A.; Miller, K. D.; Krop, I.; Ma, C. X.; LoRusso, P. M.; Munster, P. N.; Campbell, K.; Gaddy, D. F.; Leonard, S. C.; Geretti, E.; Blocker, S. J.; Kirpotin, D. B.; Moyo, V.; Wickham, T. J.; Hendriks, B. S. ${ }^{64} \mathrm{Cu}-\mathrm{MM}-302$ Positron Emission Tomography Quantifies Variability of Enhanced Permeability and Retention of Nanoparticles in Relation to Treatment Response in Patients with Metastatic Breast Cancer. Clin. Cancer Res. 2017, 23, 4190-4202. 
(8) Dearling, J. L. J.; Packard, A. B. Molecular Imaging in Nanomedicine - A Developmental Tool and a Clinical Necessity. J. Controlled Release 2017, 261, 23-30.

(9) Perez-Medina, C.; Abdel-Atti, D.; Tang, J.; Zhao, Y.; Fayad, Z. A.; Lewis, J. S.; Mulder, W. J. M.; Reiner, T. Nanoreporter PET Predicts the Efficacy of Anti-Cancer Nanotherapy. Nat. Commun. 2016, 7, 11838.

(10) Ramanathan, R. K.; Korn, R. L.; Raghunand, N.; Sachdev, J. C.; Newbold, R. G.; Jameson, G.; Fetterly, G. J.; Prey, J.; Klinz, S. G.; Kim, J.; Cain, J.; Hendriks, B. S.; Drummond, D. C.; Bayever, E.; Fitzgerald, J. B. Correlation between Ferumoxytol Uptake in Tumor Lesions by MRI and Response to Nanoliposomal Irinotecan in Patients with Advanced Solid Tumors: A Pilot Study. Clin. Cancer Res. 2017, 23, 3638-3648.

(11) Harrington, K. J.; Mohammadtaghi, S.; Uster, P. S.; Glass, D.; Peters, A. M.; Vile, R. G.; Stewart, J. S. W. Effective Targeting of Solid Tumors in Patients with Locally Advanced Cancers by Radiolabeled Pegylated Liposomes. Clin. Cancer Res. 2001, 7, 243-254.

(12) Arrieta, O.; Medina, L. A.; Estrada-Lobato, E.; Ramirez-Tirado, L. A.; Mendoza-Garcia, V. O.; de la Garza-Salazar, J. High Liposomal Doxorubicin Tumour Tissue Distribution, As Determined by Radiopharmaceutical Labelling with ${ }^{99 \mathrm{~m}} \mathrm{Tc}$-LD, Is Associated with the Response and Survival of Patients with Unresectable Pleural Mesothelioma Treated with a Combination of Liposomal Doxorubicin and Cisplatin. Cancer Chemother. Pharmacol. 2014, 74, 211-215.

(13) Sun, D. Nanotheranostics: Integration of Imaging and Targeted Drug Delivery. Mol. Pharmaceutics 2010, 7, 1879.

(14) Nayak, T. K.; Brechbiel, M. W. Radioimmunoimaging with Longer-Lived Positron-Emitting Radionuclides: Potentials and Challenges. Bioconjugate Chem. 2009, 20, 825-841.

(15) Forster, G. J.; Engelbach, M. J.; Brockmann, J. J.; Reber, H. J.; Buchholz, H. G.; Macke, H. R.; Rosch, F. R.; Herzog, H. R.; Bartenstein, P. R. Preliminary Data on Biodistribution and Dosimetry for Therapy Planning of Somatostatin Receptor Positive Tumours: Comparison of ${ }^{86}$ Y-DOTATOC and ${ }^{111}$ In-DTPA-Octreotide. Eur. J. Nucl. Med. Mol. Imaging 2001, 28, 1743-1750.

(16) Borjesson, P. K. E.; Jauw, Y. W. S.; de Bree, R.; Roos, J. C.; Castelijns, J. A.; Leemans, C. R.; van Dongen, G. A. M. S.; Boellaard, R. Radiation Dosimetry of ${ }^{89} \mathrm{Zr}$-Labeled Chimeric Monoclonal Antibody U36 as Used for Immuno-PET in Head and Neck Cancer Patients. J. Nucl. Med. 2009, 50, 1828-1836.

(17) Zechmann, C. M.; Afshar-Oromieh, A.; Armor, T.; Stubbs, J. B.; Mier, W.; Hadaschik, B.; Joyal, J.; Kopka, K.; Debus, J.; Babich, J. W.; Haberkorn, U. Radiation Dosimetry and First Therapy Results with a ${ }^{124} \mathrm{I} /{ }^{131} \mathrm{I}$-Labeled Small Molecule (MIP-1095) Targeting PSMA for Prostate Cancer Therapy. Eur. J. Nucl. Med. Mol. Imaging 2014, 41, $1280-1292$.

(18) Reardan, D. T.; Meares, C. F.; Goodwin, D. A.; Mctigue, M.; David, G. S.; Stone, M. R.; Leung, J. P.; Bartholomew, R. M.; Frincke, J. M. Antibodies against Metal-Chelates. Nature 1985, 316, 265-268.

(19) Goodwin, D. A.; Mears, C. F.; Mctigue, M.; David, G. S. Monoclonal-Antibody Hapten Radiopharmaceutical Delivery. Nucl. Med. Commun. 1986, 7, 569-580.

(20) Steen, E. J. L.; Edem, P. E.; Norregaard, K.; Jorgensen, J. T.; Shalgunov, V.; Kjaer, A.; Herth, M. M. Pretargeting in Nuclear Imaging and Radionuclide Therapy: Improving Efficacy of Theranostics and Nanomedicines. Biomaterials 2018, 179, 209-245.

(21) Dube, D. H.; Bertozzi, C. R. Metabolic Oligosaccharide Engineering as a Tool for Glycobiology. Curr. Opin. Chem. Biol. 2003, 7, 616-625.

(22) Blackman, M. L.; Royzen, M.; Fox, J. M. Tetrazine Ligation: Fast Bioconjugation Based on Inverse-Electron-Demand Diels-Alder Reactivity. J. Am. Chem. Soc. 2008, 130, 13518-13519.

(23) Darko, A.; Wallace, S.; Dmitrenko, O.; Machovina, M. M.; Mehl, R. A.; Chin, J. W.; Fox, J. M. Conformationally Strained TransCyclooctene with Improved Stability and Excellent Reactivity in Tetrazine Ligation. Chem. Sci. 2014, 5, 3770-3776.

(24) Herth, M. M.; Andersen, V. L.; Lehel, S.; Madsen, J.; Knudsen, G. M.; Kristensen, J. L. Development of a ${ }^{11} \mathrm{C}$-Labeled Tetrazine for Rapid Tetrazine-Trans-Cyclooctene Ligation. Chem. Commun. 2013, 49, $3805-3807$
(25) Steen, E. J. L.; Jorgensen, J. T.; Petersen, I. N.; Norregaard, K.; Lehel, S.; Shalgunov, V.; Birke, A.; Edem, P. E.; L’Estrade, E. T.; Hansen, H. D.; Villadsen, J.; Erlandsson, M.; Ohlsson, T.; Yazdani, A.; Valliant, J. F.; Kristensen, J. L.; Barz, M.; Knudsen, G. M.; Kjaer, A.; Herth, M. M. Improved Radiosynthesis and Preliminary In Vivo Evaluation of the ${ }^{11} \mathrm{C}$-Labeled Tetrazine $\left[{ }^{11} \mathrm{C}\right] \mathrm{AE}-1$ for Pretargeted PET Imaging. Bioorg. Med. Chem. Lett. 2019, 29, 986-990.

(26) Edem, P. E.; Sinnes, J. P.; Pektor, S.; Bausbacher, N.; Rossin, R.; Yazdani, A.; Miederer, M.; Kjaer, A.; Valliant, J. F.; Robillard, M. S.; Rosch, F.; Herth, M. M. Evaluation of the Inverse Electron Demand Diels-Alder Reaction in Rats Using a Scandium-44-Labelled Tetrazine for Pretargeted PET Imaging. EJNMMI Res. 2019, 9, 49-56.

(27) Rossin, R.; Renart Verkerk, P.; van den Bosch, S. M.; Vulders, R. C. M.; Verel, I.; Lub, J.; Robillard, M. S. In Vivo Chemistry for Pretargeted Tumor Imaging in Live Mice. Angew. Chem., Int. Ed. 2010, 49, 3375-3378.

(28) Zeglis, B. M.; Sevak, K. K.; Reiner, T.; Mohindra, P.; Carlin, S. D.; Zanzonico, P.; Weissleder, R.; Lewis, J. S. A Pretargeted PET Imaging Strategy Based on Bioorthogonal Diels-Alder Click Chemistry. J. Nucl. Med. 2013, 54, 1389-1396.

(29) Zeglis, B. M.; Brand, C.; Abdel-Atti, D.; Carnazza, K. E.; Cook, B. E.; Carlin, S.; Reiner, T.; Lewis, J. S. Optimization of a Pretargeted Strategy for the PET Imaging of Colorectal Carcinoma via the Modulation of Radioligand Pharmacokinetics. Mol. Pharmaceutics 2015, 12, 3575-3587.

(30) Meyer, J. P.; Houghton, J. L.; Kozlowski, P.; Abdel-Atti, D.; Reiner, T.; Pillarsetty, N. V.; Scholz, W. W.; Zeglis, B. M.; Lewis, J. S. ${ }^{18}$ F-Based Pretargeted PET Imaging Based on Bioorthogonal DielsAlder Click Chemistry. Bioconjugate Chem. 2016, 27, 298-301.

(31) Meyer, J. P.; Kozlowski, P.; Jackson, J.; Cunanan, K. M.; Adumeau, P.; Dilling, T. R.; Zeglis, B. M.; Lewis, J. S. Exploring Structural Parameters for Pretargeting Radioligand Optimization. J. Med. Chem. 2017, 60, 8201-8217.

(32) Keinanen, O.; Fung, K.; Pourat, J.; Jallinoja, V.; Vivier, D.; Pillarsetty, N. K.; Airaksinen, A. J.; Lewis, J. S.; Zeglis, B. M.; Sarparanta, M. Pretargeting of Internalizing Trastuzumab and Cetuximab with a $\left[{ }^{18} \mathrm{~F}\right]$ Tetrazine Tracer in Xenograft Models. EJNMMI Res. 2017, 7, 95106.

(33) Schumacher, D.; Hackenberger, C. P.; Leonhardt, H.; Helma, J. Current Status: Site-Specific Antibody Drug Conjugates. J. Clin. Immunol. 2016, 36, 100-107.

(34) Agarwal, P.; Bertozzi, C. R. Site-Specific Antibody-Drug Conjugates: The Nexus of Bioorthogonal Chemistry, Protein Engineering, and Drug Development. Bioconjugate Chem. 2015, 26, 176-192.

(35) Hou, S.; Choi, J. S.; Garcia, M. A.; Xing, Y.; Chen, K. J.; Chen, Y. M.; Jiang, Z. K.; Ro, T.; Wu, L.; Stout, D. B.; Tomlinson, J. S.; Wang, H.; Chen, K.; Tseng, H. R.; Lin, W. Y. Pretargeted Positron Emission Tomography Imaging That Employs Supramolecular Nanoparticles with In Vivo Bioorthogonal Chemistry. ACS Nano 2016, 10, 14171424.

(36) Rossin, R.; van Duijnhoven, S. M.; Lappchen, T.; van den Bosch, S. M.; Robillard, M. S. Trans-Cyclooctene Tag with Improved Properties for Tumor Pretargeting with the Diels-Alder Reaction. Mol. Pharmaceutics 2014, 11, 3090-3096.

(37) Rossin, R.; van den Bosch, S. M.; Ten Hoeve, W.; Carvelli, M.; Versteegen, R. M.; Lub, J.; Robillard, M. S. Highly Reactive TransCyclooctene Tags with Improved Stability for Diels-Alder Chemistry in Living Systems. Bioconjugate Chem. 2013, 24, 1210-1217.

(38) Birke, A.; Huesmann, D.; Kelsch, A.; Weilbacher, M.; Xie, J.; Bros, M.; Bopp, T.; Becker, C.; Landfester, K.; Barz, M. PolypeptoidBlock-Polypeptide Copolymers: Synthesis, Characterization, and Application of Amphiphilic Block Copolypept(o)ides in Drug Formulations and Miniemulsion Techniques. Biomacromolecules 2014, 15, 548-557.

(39) Hortz, C.; Birke, A.; Kaps, L.; Decker, S.; Wachtersbach, E.; Fischer, K.; Schuppan, D.; Barz, M.; Schmidt, M. Cylindrical Brush Polymers with Polysarcosine Side Chains: A Novel Biocompatible Carrier for Biomedical Applications. Macromolecules 2015, 48, 20742086. 
(40) Klinker, K.; Barz, M. Polypept(o)ides: Hybrid Systems Based on Polypeptides and Polypeptoids. Macromol. Rapid Commun. 2015, 36, 1943-1957.

(41) Klinker, K.; Schafer, O.; Huesmann, D.; Bauer, T.; Capeloa, L.; Braun, L.; Stergiou, N.; Schinnerer, M.; Dirisala, A.; Miyata, K.; Osada, K.; Cabral, H.; Kataoka, K.; Barz, M. Secondary-Structure-Driven SelfAssembly of Reactive Polypept(o)ides: Controlling Size, Shape, and Function of Core Cross-Linked Nanostructures. Angew. Chem., Int. Ed. 2017, 56, 9608-9613.

(42) Luxenhofer, R.; Fetsch, C.; Grossmann, A. Polypeptoids: A Perfect Match for Molecular Definition and Macromolecular Engineering? J. Polym. Sci., Part A: Polym. Chem. 2013, 51, 2731-2752.

(43) Tanisaka, H.; Kizaka-Kondoh, S.; Makino, A.; Tanaka, S.; Hiraoka, M.; Kimura, S. Near-Infrared Fluorescent Labeled Peptosome for Application to Cancer Imaging. Bioconjugate Chem. 2008, 19, 109117.

(44) Fenaroli, F.; Repnik, U.; Xu, Y.; Johann, K.; Van Herck, S.; Dey, P.; Skjeldal, F. M.; Frei, D. M.; Bagherifam, S.; Kocere, A.; Haag, R.; De Geest, B. G.; Barz, M.; Russell, D. G.; Griffiths, G. Enhanced Permeability and Retention-Like Extravasation of Nanoparticles from the Vasculature into Tuberculosis Granulomas in Zebrafish and Mouse Models. ACS Nano 2018, 12, 8646-8661.

(45) Smoluchowski, M. Versuch einer Mathematischen Theorie der Koagulationskinetik Kolloider Loesungen. Z. Phys. Chem. 1918, 92, 129-168.

(46) Meimetis, L. G.; Carlson, J. C.; Giedt, R. J.; Kohler, R. H.; Weissleder, R. Ultrafluorogenic Coumarin-Tetrazine Probes for RealTime Biological Imaging. Angew. Chem., Int. Ed. 2014, 53, 7531-7534.

(47) Denk, C.; Svatunek, D.; Mairinger, S.; Stanek, J.; Filip, T.; Matscheko, D.; Kuntner, C.; Wanek, T.; Mikula, H. Design, Synthesis, and Evaluation of a Low-Molecular-Weight ${ }^{11} \mathrm{C}$-Labeled Tetrazine for Pretargeted PET Imaging Applying Bioorthogonal In Vivo Click Chemistry. Bioconjugate Chem. 2016, 27, 1707-1712.

(48) Andrews, P. R.; Craik, D. J.; Martin, J. L. Functional Group Contributions to Drug-Receptor Interactions. J. Med. Chem. 1984, 27, $1648-1657$.

(49) Strobl, G. The Physics of Polymers, 3rd ed.; Springer: Heidelberg, 2007.

(50) Humphrey, W.; Dalke, A.; Schulten, K. VMD: Visual Molecular Dynamics. J. Mol. Graphics 1996, 14, 33-38.

(51) Fischer, K.; Schmidt, M. Pitfalls and Novel Applications of Particle Sizing by Dynamic Light Scattering. Biomaterials 2016, 98, 7991.

(52) Kunjachan, S.; Pola, R.; Gremse, F.; Theek, B.; Ehling, J.; Moeckel, D.; Hermanns-Sachweh, B.; Pechar, M.; Ulbrich, K.; Hennink, W. E.; Storm, G.; Lederle, W.; Kiessling, F.; Lammers, T. Passive versus Active Tumor Targeting Using RGD- and NGRModified Polymeric Nanomedicines. Nano Lett. 2014, 14, 972-981.

(53) Wilhelm, S.; Tavares, A. J.; Dai, Q.; Ohta, S.; Audet, J.; Dvorak, H. F.; Chan, W. C. W. Analysis of Nanoparticle Delivery to Tumours. Nat. Rev. Mater. 2016, 1, 16014.

(54) Rossin, R.; Lappchen, T.; van den Bosch, S. M.; Laforest, R.; Robillard, M. S. Diels-Alder Reaction for Tumor Pretargeting: In Vivo Chemistry Can Boost Tumor Radiation Dose Compared with Directly Labeled Antibody. J. Nucl. Med. 2013, 54, 1989-1995.

(55) Selvaraj, R.; Fox, J. M. An Efficient and Mild Oxidant for the Synthesis of S-Tetrazines. Tetrahedron Lett. 2014, 55, 4795-4797.

(56) Versteegen, R. M.; Rossin, R.; ten Hoeve, W.; Janssen, H. M.; Robillard, M. S. Click To Release: Instantaneous Doxorubicin Elimination Upon Tetrazine Ligation. Angew. Chem., Int. Ed. 2013, 52, 14112-14116.

(57) Conejos-Sanchez, I.; Duro-Castano, A.; Birke, A.; Barz, M.; Vicent, M. J. A Controlled and Versatile NCA Polymerization Method for the Synthesis of Polypeptides. Polym. Chem. 2013, 4, 3182-3186.

(58) Weber, B.; Birke, A.; Fischer, K.; Schmidt, M.; Barz, M. Solution Properties of Polysarcosine: From Absolute and Relative Molar Mass Determinations to Complement Activation. Macromolecules 2018, 51, 2653-2661.
(59) Kunishima, M.; Kawachi, C.; Iwasaki, F.; Terao, K.; Tani, S. Synthesis and Characterization of 4-(4,6-Dimethoxy-1,3,5-Triazin-2yl)-4-Methylmorpholinium Chloride. Tetrahedron Lett. 1999, 40, 5327-5330. 